\title{
Control Strategy for Three-Phase PWM Boost Rectifier Operating Under Different SupplyVoltage Conditions
}

\author{
Asst.Prof.Dr. Turki Kahawish Hassan \\ Department of Electrical Engineering \\ University of AL-Mustansiriya \\ Baghdad, Iraq \\ eng.turkik hasan@uomustansiriyah.edu.i
}

\author{
Muntadher Kadhem Abdullah \\ Department of Electrical Engineering \\ University of AL-Mustansiriya \\ Baghdad, Iraq \\ montadherkadhemm@gmail.com
}

\begin{abstract}
In this paper, a proposed control strategy is presented to improve the performance of the pulse width modulation (PWM) boost type rectifier when operating under different supply voltage conditions (balanced, unbalanced, and distorted three-phase supply voltages). The proposed control strategy is divided into two parts, the first part is voltage controller and the second part is current controller. In the voltage controller, Repetitive Controller $(R C)$ is used to reduce the even order harmonics in the regulated output dc voltage so small output capacitor (filter) is used instead of large capacitor. RC also reduces the even order harmonics which appear in the reflected dc current $\left(I_{\text {MAX }}\right)$, this leads to reduce the odd order harmonics which appear in the input currents. While in the current controller, Enhanced Phase Locked Loop (EPLL) technique is used to obtain sinusoidal and balanced three phases, to construct the reference currents, which are in phase with the fundamental supply voltages. Therefore, the supply-side power factor is kept close to unity. A proportional controller is used to give excellent tracking between the line and the reference currents. The complete system with the proposed control strategy are simulated using Matlab/Simulink. The results for the complete system using repetitive voltage controller are obtained and compared to the results of the system with the conventional voltage controller (Proportional-Integral (PI) controller connected in series with a Low Pass Filter (LPF)). The results with the repetitive controller show better response and stable operation in the steady state under different input voltage conditions, as well as in the transient response under changing the load condition.
\end{abstract}

Index Terms-Enhanced Phase Locked Loop,Repetitive Controller,Three-Phase PWM Boost Rectifier, Proportional-Integral controller.

I. INTRODUCTION

The boost type PWM rectifier has been increasingly employed in recent years since it offers the possibility of a low distortion line current withnear unity power factor for any load condition. Another advantage over traditional phase-controlled thyristor rectifiers is its capability for nearly instantaneous reversal of power flow. Unfortunately, the features of the PWM boost type rectifier are fully realized only when the supply three phase input voltages are balanced. It has been shown that unbalanced input voltages cause an abnormal second order harmonic at the dc output voltage, which reflects back to the input causing third-order harmonic current to flow. Next, the third-order harmonic current causes a fourth-order harmonic voltage on the dc bus, and so on. This results in the appearance of even harmonics at the dc output and odd harmonics in the input currents. An attempt was made to reduce low order harmonics at the input and the output of the PWM Boost Type Rectifier under unbalance input voltages [1]. The authors in [2] used two synchronous reference frames: a positivesequence current regulated by a 
proportional integral (PI) controller in a positive synchronous reference frame (SRF), and a negative sequence current regulated by a PI controller in a negative SRF. In [3], a new control scheme is proposed to minimize harmonic distortions of the input current and dc-link voltage in the converter. A hybrid digitalrepetitive current controller (RC) is used to minimize the line-side current harmonics and the dc link voltage harmonics under the distorted and unbalanced operating conditions [4]. But these strategies require a series of frame transformation and calculation which increase the complexity of implementation. New control method for input-output harmonic elimination of the pulse width modulation(PWM) boost-type rectifier under conditions of both unbalancedinput voltages and unbalanced input impedances is presented in [5]. But in this method, hysteresis current controllers are used to regulate the actual three-phase currents, these controllers produce drawbacks such as a variable switching frequency and an irregularity of the position of modulation pulses. These drawbacks provide high current ripples, acoustic noise, and difficulty in designing of input filter.

In [6], a new method for control of PWM rectifiers is presented. This method is classified in Direct Power Control (DPC) group among different control methods for PWM rectifiers which uses Model Predictive Control (MPC) and SVM. The method also usesVirtual Flux (VF) vector of the input voltage, which improves the performance of the rectifier under harmonic conditions of the networks, the method has several advantages: simple, it uses constant switching frequency, and excellent step response. Alsothis method has some disadvantages: the unbalanced condition at the input voltages is not discussed, only balanced and 5\% level of $5^{\text {th }}$ order harmonic distortion was discussed. This level of distortion is very low compared to the level used in this paper. Another disadvantage inthis method is that it uses large input inductances as well as large output capacitor.

In this paper, the proposed method can be divided into two parts; the first part is voltage controller (Repetitive Controller) to produce the magnitude of the reference currents ( $\left.\mathrm{I}_{\mathrm{MAX}}\right)$ without even order harmonics. The second part is current controller (Enhanced phase locked loops are used) to produce pure and balanced sine waves, these sine waves multiplied by the output of the voltage controller ( $\mathrm{I}_{\mathrm{MAX}}$ ) to obtain sinusoidal reference currents. Finally proportional controllers are used to force the line currents to follow these sinusoidal references.

\section{MODELING OF THREE- PHASE PWM BOOST RECTIFIER UNDER BALANCED INPUT VOLTAGE CONDITION}

The main circuit of the three phases PWM ac to dc converter is shown in Figure1. Three-phase line voltages and the balanced input line currents are:

$$
\begin{aligned}
& \mathrm{e}_{1}=E_{\mathrm{m}} \sin (\omega \mathrm{t}) \\
& \mathrm{e}_{2}=\mathrm{E}_{\mathrm{m}} \sin (\omega \mathrm{t}-120) \\
& \mathrm{e}_{3}=\mathrm{E}_{\mathrm{m}} \sin (\omega \mathrm{t}+120)
\end{aligned}
$$

Assume unity power factor

$$
\begin{aligned}
& \mathrm{i}_{1}=\mathrm{I}_{\mathrm{m}} \sin (\omega \mathrm{t}) \\
& \mathrm{i}_{2}=\mathrm{I}_{\mathrm{m}} \sin (\omega \mathrm{t}-120) \\
& \mathrm{i}_{3}=\mathrm{I}_{\mathrm{m}} \sin (\omega \mathrm{t}+120)
\end{aligned}
$$

Where $\mathrm{E}_{\mathrm{m}}\left(\mathrm{I}_{\mathrm{m}}\right)$ and $\omega$ are amplitude of the phase voltage (current) and angular frequency, respectively. For phase 1: [7]

$\mathrm{L} \frac{\mathrm{di}_{1}}{\mathrm{dt}}+\mathrm{R}_{\mathrm{L}} \mathrm{i}_{1}=\mathrm{V}_{\mathrm{AD}}=\mathrm{e}_{1}-\left(\mathrm{V}_{\mathrm{DN}}+\mathrm{V}_{\mathrm{NO}}\right)$

When switch $\mathrm{S}_{1}$ is $\mathrm{ON}$ and switch $\mathrm{S}_{1}{ }^{\prime}$ is $\mathrm{OFF}$, the switching functionis:

$\mathrm{d}_{1}=1$ and $\mathrm{d}_{1}{ }^{\prime}=0$ 


$$
\mathrm{V}_{\mathrm{DN}}=\mathrm{i}_{1} \mathrm{R}_{\mathrm{S}}+\mathrm{V}_{\mathrm{o}}
$$

Where $R_{S}$ is equivalent resistance of a switching device. When switch $\mathrm{S}_{1}{ }^{\prime}$ is $\mathrm{ON}$, the switching function is:

$\mathrm{d}_{1}=0 \quad$ and $\quad \mathrm{d}_{1}{ }^{\prime}=1 \quad$ and

$\mathrm{V}_{\mathrm{DN}}=\mathrm{i}_{1} \mathrm{R}_{\mathrm{S}}$

Therefore,equation (3) becomes:

$\mathrm{L} \frac{\mathrm{di}_{1}}{\mathrm{dt}}+\mathrm{R}_{\mathrm{L}} \mathrm{i}_{1}=\mathrm{e}_{1}-\left[\left(\mathrm{i}_{1} \mathrm{R}_{\mathrm{S}}+\mathrm{V}_{\mathrm{o}}\right) \mathrm{d}_{1}+\left(\mathrm{i}_{1} \mathrm{R}_{\mathrm{S}}\right) \mathrm{d}_{1}{ }^{\prime}\right.$

$\left.+\mathrm{V}_{\mathrm{NO}}\right]$

Because either $\mathrm{S}_{1}$ or $\mathrm{S}_{1}{ }^{\prime}$ is conducting and only one of them is allowed to conduct in any moment, i.e. :

$\mathrm{d}_{1}+\mathrm{d}_{1}^{\prime}=1$ so

$L \frac{d i_{1}}{d t}+R_{L} i_{1}=e_{1}-\left[i_{1} R_{S} d_{1}+V_{o} d_{1}+i_{1} R_{S} d_{1}{ }^{\prime}\right.$

$+\mathrm{V}_{\mathrm{NO}}$ ]

$\mathrm{L} \frac{\mathrm{di}_{1}}{\mathrm{dt}}+\mathrm{R}_{\mathrm{L}} \mathrm{i}_{1}=\mathrm{e}_{1}-\left[\mathrm{i}_{1} \mathrm{R}_{\mathrm{S}}\left(\mathrm{d}_{1}+\mathrm{d}_{1}{ }^{\prime}\right)+\mathrm{V}_{\mathrm{o}} \mathrm{d}_{1}\right.$

$\left.+\mathrm{V}_{\mathrm{NO}}\right]$

$L \frac{d i_{1}}{d t}+R_{L} i_{1}+R_{S} i_{1}=e_{1}-\left[V_{o} d_{1}+V_{N O}\right]$

$\mathrm{L} \frac{\mathrm{di}_{1}}{\mathrm{dt}}+\mathrm{R} \mathrm{i}_{1}=\mathrm{e}_{1}-\left[\mathrm{V}_{\mathrm{o}} \mathrm{d}_{1}+\mathrm{V}_{\mathrm{NO}}\right]$

Where $\mathrm{R}=\mathrm{R}_{\mathrm{L}}+\mathrm{R}_{\mathrm{S}}$, the total series resistance in one phase. Similarly, for phase 2 and 3: [7]

$\mathrm{L} \frac{\mathrm{di}_{2}}{\mathrm{dt}}+\mathrm{R} \mathrm{i}_{2}=\mathrm{e}_{2}-\left[\mathrm{V}_{\mathrm{o}} \mathrm{d}_{2}+\mathrm{V}_{\mathrm{NO}}\right]$

$\mathrm{L} \frac{\mathrm{di}_{3}}{\mathrm{dt}}+\mathrm{R} \mathrm{i}_{3}=\mathrm{e}_{3}-\left[\mathrm{V}_{\mathrm{o}} \mathrm{d}_{3}+\mathrm{V}_{\mathrm{NO}}\right]$

For a three-phase system without neutral line,

$\mathrm{i}_{1}+\mathrm{i}_{2}+\mathrm{i}_{3}=0$

The sum of three phase supply is

$\mathrm{e}_{1}+\mathrm{e}_{2}+\mathrm{e}_{3}=0$

The voltage $\mathrm{V}_{\mathrm{NO}}$ can be obtained by addingequations (10),(11), and(12)
$\mathrm{L} \frac{\mathrm{di}_{1}}{\mathrm{dt}}+\mathrm{L} \frac{\mathrm{di}_{2}}{\mathrm{dt}}+\mathrm{L} \frac{\mathrm{di}_{3}}{\mathrm{dt}}+\mathrm{R}\left(\mathrm{i}_{1}+\mathrm{i}_{2}+\mathrm{i}_{3}\right)=\mathrm{e}_{1}+\mathrm{e}_{2}+\mathrm{e}_{3}-\mathrm{V}_{\mathrm{o}}{ }^{*}$

$\left(\mathrm{d}_{1}+\mathrm{d}_{2}+\mathrm{d}_{3}\right)+3 \mathrm{~V}_{\mathrm{NO}}$

$0=\mathrm{V}_{\mathrm{o}}\left(\mathrm{d}_{1}+\mathrm{d}_{2}+\mathrm{d}_{3}\right)+3 \mathrm{~V}_{\mathrm{NO}}$

$\mathrm{V}_{\mathrm{NO}}=\frac{-1}{3} \mathrm{~V}_{\mathrm{o}} \sum_{\mathrm{k}=1}^{3} \mathrm{~d}_{\mathrm{k}}$

Substitute equation (16) in equations (10), (11), and (12), the result will be

$\mathrm{L} \frac{\mathrm{di}_{1}}{\mathrm{dt}}+\mathrm{R} \mathrm{i}_{1}=\mathrm{e}_{1}-\mathrm{u}_{\mathrm{s} 1}$

$\mathrm{L} \frac{\mathrm{di}_{2}}{\mathrm{dt}}+\mathrm{Ri}_{2}=\mathrm{e}_{2}-\mathrm{u}_{\mathrm{s} 2}$

$\mathrm{L} \frac{\mathrm{di}_{3}}{\mathrm{dt}}+\mathrm{Ri}_{3}=\mathrm{e}_{3}-\mathrm{u}_{\mathrm{s} 3}$

Where

$\mathrm{u}_{\mathrm{s} 1}=\mathrm{V}_{\mathrm{o}}\left(\frac{2 \mathrm{~d}_{1}-\left(\mathrm{d}_{2}+\mathrm{d}_{3}\right)}{3}\right)$

$\mathrm{u}_{\mathrm{s} 2}=\mathrm{V}_{\mathrm{o}}\left(\frac{2 \mathrm{~d}_{2}-\left(\mathrm{d}_{1}+\mathrm{d}_{3}\right)}{3}\right)$

$\mathrm{u}_{\mathrm{s} 3}=\mathrm{V}_{\mathrm{o}}\left(\frac{2 \mathrm{~d}_{3}-\left(\mathrm{d}_{1}+\mathrm{d}_{2}\right)}{3}\right)$

In the Figure1, the input line current for each phase is multiplied by switching function, then adding them to result output current $i_{\mathrm{dc}}$, i.e:

$\mathrm{i}_{\mathrm{dc}}=\mathrm{i}_{1} \mathrm{~d}_{1}+\mathrm{i}_{2} \mathrm{~d}_{2}+\mathrm{i}_{3} \mathrm{~d}_{3}$

According to Figure 1, the output current $i_{d c}$ is equal to:

$\mathrm{i}_{\mathrm{dc}}=\mathrm{i}_{\mathrm{c}}+\mathrm{I}_{\mathrm{o}}$

Where $i_{c}\left(C \frac{d V_{o}}{d t}\right)$ is the current of the output capacitor while $I_{0}$ is the dc load current $\left(\mathrm{I}_{\mathrm{o}}=\frac{\mathrm{V}_{\mathrm{O}}}{\mathrm{R}_{\mathrm{o}}}\right)$. Soanother differential equation can be written as:

$\mathrm{C} \frac{\mathrm{dV}_{\mathrm{o}}}{\mathrm{dt}}=\mathrm{i}_{1} \mathrm{~d}_{1}+\mathrm{i}_{2} \mathrm{~d}_{2}+\mathrm{i}_{3} \mathrm{~d}_{3}-\frac{\mathrm{V}_{\mathrm{o}}}{\mathrm{Ro}}$

(24) 


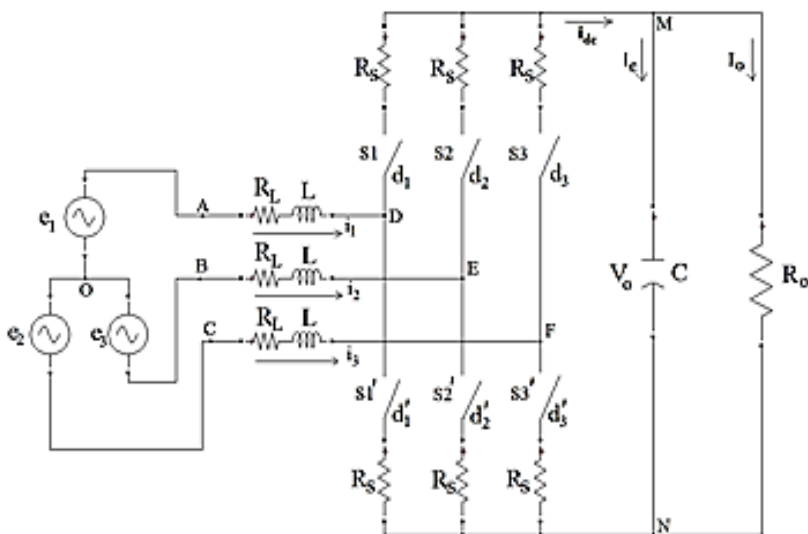

Figure1: Circuit of PWM rectifier

A block diagram of the PWM rectifier with $\mathrm{ABC}$ model is presented in Figure2.

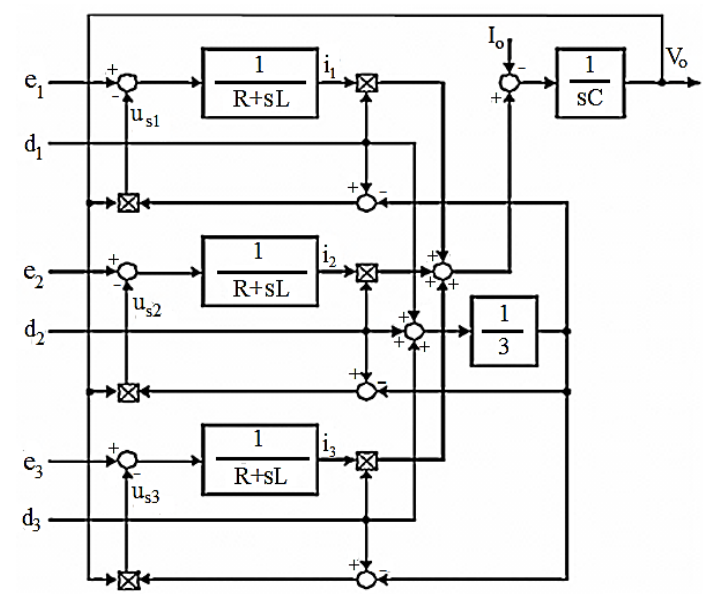

Figure2: PWM rectifier in ABC- model

III. ANALYSIS OF THREEPHASE PWM BOOST RECTIFIER UNDER UNBALANCED INPUT VOLTAGE CONDITION

In Figure1, it is assumed that the PWM rectifier is supplied by unbalanced input voltages but balanced input impedances. The assumptions used in the following derivation are

1) The system losses are very small and can be neglected.

2) The switching functions used to represent switching action of the converter are unbalanced but contain no zero sequence.
3) Only fundamental components of switching functions and input currents are taken into account (PWM switching harmonics are not considered).

4) There is no phase difference between fundamental components of the switching functions and the input currents. Sothat the fundamental component of the switching functions can be written as

$$
\begin{aligned}
& \mathrm{d}_{\mathrm{f} 1}=\mathrm{A}_{1} \sin (\omega \mathrm{t}) \\
& \mathrm{d}_{\mathrm{f} 2}=\mathrm{A}_{2} \sin (\omega \mathrm{t}-120) \\
& \mathrm{d}_{\mathrm{f} 3}=\mathrm{A}_{3} \sin (\omega \mathrm{t}+120)
\end{aligned}
$$

And the unbalanced input currents can be written as

$$
\begin{aligned}
& \mathrm{i}_{1}=\mathrm{I}_{\mathrm{m} 1} \sin (\omega \mathrm{t}) \\
& \mathrm{i}_{2}=\mathrm{I}_{\mathrm{m} 2} \sin (\omega \mathrm{t}-120) \\
& \mathrm{i}_{3}=\mathrm{I}_{\mathrm{m} 3} \sin (\omega \mathrm{t}+120)
\end{aligned}
$$

The output dc current is

$\mathrm{i}_{\mathrm{dc}}=\overline{\mathrm{T}} . \overline{\mathrm{i}}$

The converter transfer function vector $\overline{\mathrm{T}}$ is composed of three switching functions.[8]

$\overline{\mathrm{T}}=\left[\begin{array}{lll}\mathrm{d}_{\mathrm{f} 1} & \mathrm{~d}_{\mathrm{f} 2} & \mathrm{~d}_{\mathrm{f3}}\end{array}\right]$

And the current ivector is

$\overline{\mathrm{i}}=\left[\begin{array}{l}\mathrm{i}_{1} \\ \mathrm{i}_{2} \\ \mathrm{i}_{3}\end{array}\right]$

The three-phase unbalanced input currents can be presented as a sum of two balanced sets of positive and negative sequence component.

$\overline{\mathrm{i}}=\overline{\mathrm{i}_{\mathrm{p}}}+\overline{\mathrm{i}_{\mathrm{n}}}$

$\overline{i_{p}}=\left[\begin{array}{c}I_{p} \sin (\omega t) \\ I_{p} \sin (\omega t-120) \\ I_{p} \sin (\omega t+120)\end{array}\right]$ 


$$
\overline{i_{n}}=\left[\begin{array}{c}
I_{n} \sin (\omega t) \\
I_{n} \sin (\omega t+120) \\
I_{n} \sin (\omega t-120)
\end{array}\right]
$$

Similarly the converter transfer function can be decomposed into two balanced sets of positive and negative sequence components under unbalanced voltages that is

$\overline{\mathrm{T}}=\overline{\mathrm{T}}_{\mathrm{p}}+\overline{\mathrm{T}}_{\mathrm{n}}$

$\bar{T}_{p}=\left[\begin{array}{c}A_{p} \sin (\omega t) \\ A_{p} \sin (\omega t-120) \\ A_{p} \sin (\omega t+120)\end{array}\right]^{T}$

$$
\bar{T}_{n}=\left[\begin{array}{c}
A_{n} \sin (\omega t) \\
A_{n} \sin (\omega t+120) \\
A_{n} \sin (\omega t-120)
\end{array}\right]^{T}
$$

Now from equation (34) to equation (39), the resultant output current in equation (31) under unbalanced input voltages becomes [8]

$$
\begin{gathered}
i_{d c}=\left(T_{p}+T_{n}\right)\left(i_{p}+i_{n}\right) \\
i_{d c}=T_{p} i_{p}+T_{p} i_{n}+T_{n} i_{p}+T_{n} i_{n}
\end{gathered}
$$

Equation (41) represents the general expression for the converter output current $i_{\mathrm{dc}}$ under unbalanced voltages in term of positive and negative sequence components of the converter transfer function and the input currents respectively.

$$
\begin{aligned}
& \mathrm{T}_{\mathrm{p}} \mathrm{i}_{\mathrm{p}}=\frac{3 \mathrm{~A}_{\mathrm{p}} \mathrm{I}_{\mathrm{p}}}{2} \\
& \mathrm{~T}_{\mathrm{n}} \mathrm{i}_{\mathrm{n}}=\frac{3 A_{\mathrm{n}} \mathrm{I}_{\mathrm{n}}}{2} \\
& \mathrm{~T}_{\mathrm{p}} \mathrm{i}_{\mathrm{n}}=\frac{-3 A_{\mathrm{p}} \mathrm{I}_{\mathrm{n}}}{2} \cos (2 \omega \mathrm{t}) \\
& \mathrm{T}_{\mathrm{n}} \mathrm{i}_{\mathrm{p}}=\frac{-3 A_{\mathrm{n}} \mathrm{I}_{\mathrm{p}}}{2} \cos (2 \omega \mathrm{t}) \\
& \mathrm{i}_{\mathrm{dc}}=\frac{3 A_{\mathrm{p}} \mathrm{I}_{\mathrm{p}}}{2}+\frac{3 A_{\mathrm{n}} \mathrm{I}_{\mathrm{n}}}{2}-\frac{3 A_{\mathrm{p}} \mathrm{I}_{\mathrm{n}}}{2} \cos (2 \omega \mathrm{t})- \\
& \frac{3 \mathrm{~A}_{\mathrm{n}} \mathrm{I}_{\mathrm{p}}}{2} \cos (2 \omega \mathrm{t})
\end{aligned}
$$

The cross product $\left(T_{p} i_{n}\right)$ and $\left(T_{n} i_{p}\right)$ yield the abnormal second order harmonics components.

$\mathrm{i}_{\mathrm{dc}}=\mathrm{I}_{\mathrm{dc}}+\mathrm{i}_{\mathrm{sh}}$

Where

$$
\begin{aligned}
& \mathrm{I}_{\mathrm{dc}}=\frac{3 A_{\mathrm{p}} \mathrm{I}_{\mathrm{p}}}{2}+\frac{3 \mathrm{~A}_{\mathrm{n}} \mathrm{I}_{\mathrm{n}}}{2} \\
& \mathrm{i}_{\mathrm{sh}}=\frac{-3 A_{\mathrm{p}} \mathrm{I}_{\mathrm{n}}}{2} \cos (2 \omega \mathrm{t})-\frac{3 A_{\mathrm{n}} \mathrm{I}_{\mathrm{p}}}{2} \cos (2 \omega \mathrm{t}) \\
& \mathrm{I}_{\mathrm{o}}=\mathrm{i}_{\mathrm{dc}}-\mathrm{C} \frac{\mathrm{dV_{ \textrm {o } }}}{\mathrm{dt}} \\
& \mathrm{I}_{\mathrm{o}}=\mathrm{I}_{\mathrm{dc}}+\mathrm{i}_{\mathrm{sh}}-\mathrm{C} \frac{\mathrm{dV_{ \textrm {o } }}}{\mathrm{dt}} \\
& \mathrm{V}_{\mathrm{o}}=\mathrm{R}_{\mathrm{o}} \mathrm{I}_{\mathrm{o}}
\end{aligned}
$$

Where $V_{o}$ and $R_{o}$ are the output $d c$ load voltage and the load resistance

$$
\begin{aligned}
& \mathrm{V}_{\mathrm{o}}=\mathrm{R}_{\mathrm{o}}\left[\mathrm{I}_{\mathrm{dc}}+\mathrm{i}_{\mathrm{sh}}-\mathrm{C} \frac{\mathrm{dV}_{\mathrm{o}}}{\mathrm{dt}}\right] \\
& \mathrm{V}_{\mathrm{o}}=\underbrace{\left[\mathrm{R}_{\mathrm{o}} \mathrm{I}_{\mathrm{dc}}-\mathrm{R}_{\mathrm{o}} \mathrm{C} \frac{\mathrm{dV_{ \textrm {o } }}}{\mathrm{dt}}\right]}_{\text {constant (pure dc value } \left.\mathrm{V}_{\mathrm{dc}}\right)}+ \\
& \underbrace{\mathrm{R}_{\mathrm{o}} \mathrm{i}_{\text {sh }}}_{\text {second order harmonic }\left(\mathrm{V}_{\mathrm{sh}}\right)} \\
& \mathrm{V}_{\mathrm{o}}=\mathrm{V}_{\mathrm{dc}}+\mathrm{V}_{\mathrm{sh}}
\end{aligned}
$$

Due to the unbalance in the input voltages, the output dc voltage contains dc term $\left(\mathrm{V}_{\mathrm{dc}}\right)$ and ac term $\left(\mathrm{V}_{\mathrm{sh}}\right)$. For a desired level $\mathrm{V}_{\mathrm{REF}}$, a controller is used to regulate the output dc voltage. Due to the existence of the harmonic voltage $\left(\mathrm{v}_{\mathrm{sh}}\right)$ in $\mathrm{V}_{\mathrm{o}}$, the output current of the voltage controller ( $\mathrm{I}_{\text {MAX }}$ ) will contain de term (I) and ac term $\left(\mathrm{I}_{\mathrm{c}} \cos (2 \omega \mathrm{t})\right)$ as shown below

$$
\mathrm{I}_{\mathrm{MAX}}=\mathrm{I}+\mathrm{I}_{\mathrm{c}} \cos (2 \omega \mathrm{t})
$$

$\mathrm{I}_{\mathrm{MAX}}$ is used as magnitude for the reference currents sothat forphase1, the reference current is

$$
\begin{aligned}
& \mathrm{i}_{\mathrm{r} 1}=\mathrm{I}_{\mathrm{MAX}} \sin (\omega \mathrm{t}) \\
& \mathrm{i}_{\mathrm{r} 1}=\mathrm{I} \sin (\omega \mathrm{t})+\mathrm{I}_{\mathrm{c}} \cos (2 \omega \mathrm{t}) \sin (\omega \mathrm{t})
\end{aligned}
$$




$$
\mathrm{i}_{\mathrm{r} 1}=\mathrm{I} \sin (\omega \mathrm{t})-\frac{\mathrm{I}_{\mathrm{c}}}{2}(\sin (\omega \mathrm{t})-\sin (3 \omega \mathrm{t})(57)
$$

It is implied from this analysis that the unbalance in the input voltages leads to appearance of second order harmonic (100 $\mathrm{Hz}$ for the $50 \mathrm{~Hz}$ supply) in the output $\mathrm{dc}$ voltage $\left(\mathrm{v}_{\mathrm{sh}}\right)$, which causes third order harmonic $(150 \mathrm{~Hz}$ for the $50 \mathrm{~Hz}$ supply) in the input current (see equation (57)). This interaction continues and results in the appearance of even order harmonics at the dc link voltage and odd order harmonics in the input currents.

\section{CONTROL STRATEGY}

After knowing the types of the dominant harmonics in the output (second order harmonic) and in the input (third order harmonic), a control strategy is needed to reduce these harmonics. The proposed control strategy is divided into two parts, the first part is a voltage controller and the second part is a current controller. Figure 3 shows the control strategy block diagram.

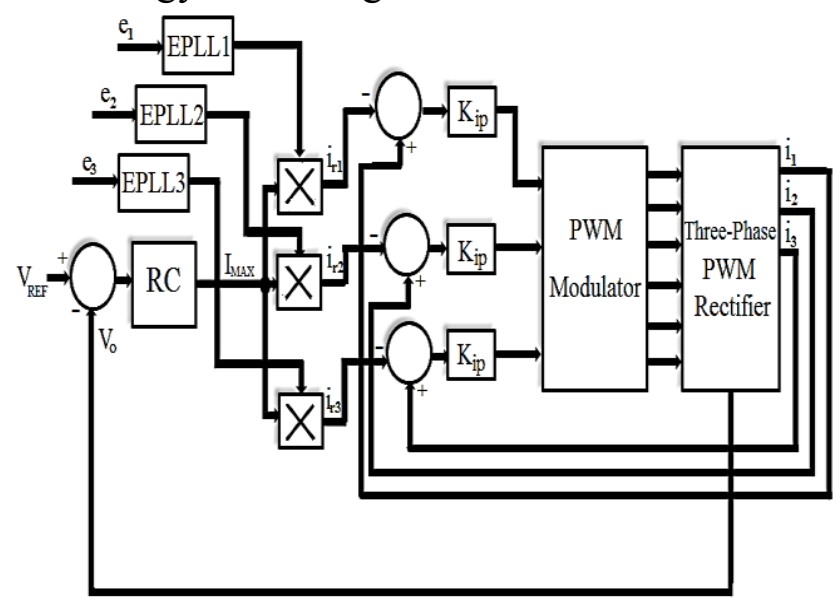

Figure 3:Overall control strategy block diagram

\section{A. Voltage Controller}

The first objective of this voltage controller is to reduce the second order harmonic in the output dc voltage (less than $5 \%$ of $\mathrm{V}_{\mathrm{o}}$ ) inequation (55), and the second objective is to reduce the second order harmonics in the reflected $\mathrm{I}_{\mathrm{MAX}}$ inequation (56). This leads to the reduction of the third order harmonics in the reference currents inequation (57), and reduces the total harmonic distortions $\left(\mathrm{THD}_{\mathrm{s}}\right)$ for these references.To achieve these objectives, there are several control schemes have been proposed based on the stationary frame and the rotating frame methods. However, most of them only consider regulation of the PWM boost type rectifier under slight to medium levels of imbalance. In order to acquire these objectives under extremely unbalanced and distorted input voltages, a Repetitive Controller (RC) is used. According to the internal model principle (IMP), zero error tracking of any reference input, in steadystate, can be accomplished if a generator of the reference input is included in a stable closed-loop system. For example, a type 1 closed-loop system with an integrator $\left(\frac{1}{\mathrm{~S}}\right)$ [or $\frac{\mathrm{z}}{\mathrm{z}-1}$ in discrete time domain], i.e., the generator of unit step function, in the loop offers tracking of a step input with zero steady state error. Repetitive control (RC) is a special case of the internal model principle in control systems with periodic signals [9]. Figure 4 shows the structure of the repetitive controller.

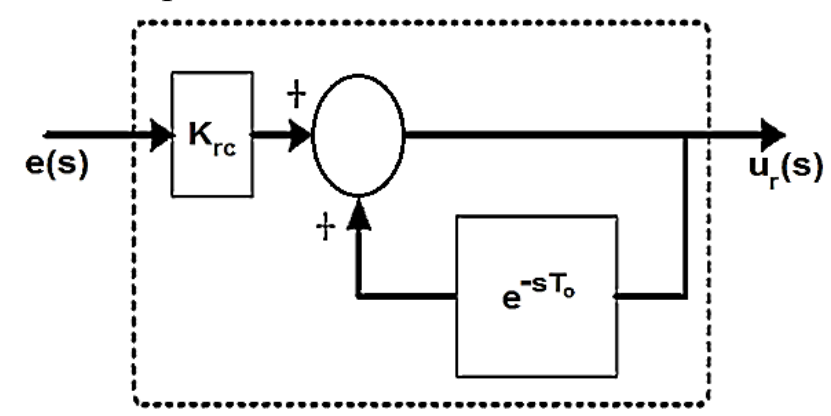

Figure 4: Repetitive controller

The transfer function of the repetitive controller is:

$$
\mathrm{G}_{\mathrm{rc}}(\mathrm{s})=\frac{\mathrm{u}_{\mathrm{r}}(\mathrm{s})}{\mathrm{e}(\mathrm{s})}=\frac{\mathrm{K}_{\mathrm{rc}}}{1-\mathrm{e}^{-\mathrm{s} \mathrm{T}_{\mathrm{o}}}}
$$

Where $\mathrm{K}_{\mathrm{rc}}$ is the gain and $\mathrm{T}_{\mathrm{o}}=\frac{1}{\mathrm{f}_{\mathrm{o}}}, \mathrm{f}_{\mathrm{o}}$ is the fundamental compensation harmonic frequency. 


$$
\begin{aligned}
& \mathrm{G}_{\mathrm{rc}}(\mathrm{s})=\frac{\mathrm{K}_{\mathrm{rc}}}{1-\mathrm{e}^{-\mathrm{sT} \mathrm{T}_{\mathrm{o}}}}=\mathrm{K}_{\mathrm{rc}}\left[\frac{1}{2}-\frac{1}{2}+\frac{1}{1-\mathrm{e}^{-s \mathrm{~T}_{\mathrm{o}}}}\right] \\
& =\mathrm{K}_{\mathrm{rc}}\left[\frac{1}{2}+\frac{2-\left(1-\mathrm{e}^{-\mathrm{sT}_{\mathrm{o}}}\right)}{2\left(1-\mathrm{e}^{-\mathrm{sT}_{\mathrm{o}}}\right)}\right] \\
& =\mathrm{K}_{\mathrm{rc}}\left[\frac{1}{2}+\frac{1+\mathrm{e}^{-\mathrm{sT}} \mathrm{o}}{2\left(1-\mathrm{e}^{-\mathrm{sT}} \mathrm{o}\right)}\right] \\
& =\mathrm{K}_{\mathrm{rc}}\left[\frac{1}{2}+\frac{1}{2}\left[\frac{1+\mathrm{e}^{-\mathrm{sT}} \mathrm{o}}{1-\mathrm{e}^{-\mathrm{sT}}}\right]\right]
\end{aligned}
$$

According to the properties of the exponential function [10]

$$
\begin{aligned}
& \pi \frac{e^{\pi x}+e^{-\pi x}}{e^{\pi x}-e^{-\pi x}} \\
& =x \sum_{K=-\infty}^{+\infty} \frac{1}{x^{2}+K^{2}} \\
& =\frac{1}{x} \\
& +\sum_{\mathrm{K}=1}^{+\infty} \frac{2 \mathrm{x}}{\mathrm{x}^{2}+\mathrm{K}^{2}} \\
& \frac{e^{\pi x}+e^{-\pi x}}{e^{\pi x}-e^{-\pi x}}=\frac{1}{\pi}\left[\frac{1}{x}+\sum_{K=1}^{+\infty} \frac{2 x}{x^{2}+K^{2}}\right] \\
& \text { If } s=x \omega_{0} \text {, where } \omega_{0}=\frac{2 \pi}{T_{0}} \text {, so } \\
& {\left[\frac{1+\mathrm{e}^{-s T_{o}}}{1-\mathrm{e}^{-s \mathrm{~T}_{\mathrm{o}}}}\right]=\left[\frac{1+\mathrm{e}^{-\mathrm{x} \frac{2 \pi \mathrm{T}_{\mathrm{o}}}{\mathrm{T}_{\mathrm{o}}}}}{1-\mathrm{e}^{-\mathrm{x} \frac{2 \pi \mathrm{T}_{\mathrm{o}}}{\mathrm{T}_{\mathrm{o}}}}}\right]=\left[\frac{1+\mathrm{e}^{-2 \pi \mathrm{x}}}{1-\mathrm{e}^{-2 \pi \mathrm{x}}}\right] .} \\
& 2 \pi\left[\frac{1+\mathrm{e}^{-2 \pi \mathrm{x}}}{1-\mathrm{e}^{-2 \pi \mathrm{x}}}\right]=\frac{1}{\mathrm{x}}+\sum_{\mathrm{K}=1}^{+\infty} \frac{2 \mathrm{x}}{\mathrm{x}^{2}+\mathrm{K}^{2}} \\
& {\left[\frac{1+\mathrm{e}^{-2 \pi \mathrm{x}}}{1-\mathrm{e}^{-2 \pi \mathrm{x}}}\right]=\frac{1}{2 \pi}\left[\frac{1}{\mathrm{x}}+\frac{2 \mathrm{x}}{\mathrm{x}^{2}+1}+\frac{2 \mathrm{x}}{\mathrm{x}^{2}+4}+\frac{2 \mathrm{x}}{\mathrm{x}^{2}+9}+\right.} \\
& \cdots] \text {, each } x=\frac{s}{\omega_{0}} \text { so } \\
& {\left[\frac{1+e^{-s T_{o}}}{1-e^{-s T_{o}}}\right]=\frac{1}{T_{o}}\left[\frac{1}{s}+\frac{2 s}{s^{2}+\omega_{o}^{2}}+\frac{2 s}{s^{2}+\left(2 \omega_{o}\right)^{2}}\right.} \\
& \left.+\frac{2 s}{s^{2}+\left(3 \omega_{0}\right)^{2}}+\cdots\right]
\end{aligned}
$$

$\mathrm{G}_{\mathrm{rc}}(\mathrm{s})=\mathrm{K}_{\mathrm{rc}}\left[\frac{1}{2}+\frac{1}{2 \mathrm{~T}_{\mathrm{o}}}\left[\frac{1}{\mathrm{~s}}+\frac{2 \mathrm{~s}}{\mathrm{~s}^{2}+\omega_{\mathrm{o}}^{2}}+\right.\right.$

$\left.\left.\frac{2 s}{s^{2}+\left(2 \omega_{0}\right)^{2}}+\frac{2 s}{s^{2}+\left(3 \omega_{0}\right)^{2}}+\cdots\right]\right]$

$\mathrm{G}_{\mathrm{rc}}(\mathrm{s})=\mathrm{K}_{\mathrm{p}}+\frac{\mathrm{K}_{\mathrm{I}}}{\mathrm{s}}+\frac{\mathrm{K}_{\mathrm{r}} \mathrm{s}}{\mathrm{s}^{2}+\omega_{\mathrm{o}}^{2}}+\frac{\mathrm{K}_{\mathrm{r}} \mathrm{s}}{\mathrm{s}^{2}+\left(2 \omega_{\mathrm{o}}\right)^{2}}+$

$\frac{\mathrm{K}_{\mathrm{r}} \mathrm{s}}{\mathrm{s}^{2}+\left(3 \omega_{\mathrm{o}}\right)^{2}}+\cdots$

Where $\mathrm{K}_{\mathrm{p}}=\frac{\mathrm{K}_{\mathrm{rc}}}{2}, \mathrm{~K}_{\mathrm{I}}=\frac{\mathrm{K}_{\mathrm{rc}}}{2 \mathrm{~T}_{\mathrm{o}}}, \mathrm{K}_{\mathrm{r}}=\frac{\mathrm{K}_{\mathrm{rc}}}{\mathrm{T}_{\mathrm{o}}}$

Mathematically, $\mathrm{RC}$ is equivalent to parallel combination of proportional controller, integral controller, and many resonant controllers, as shown in Figure 5. [11]

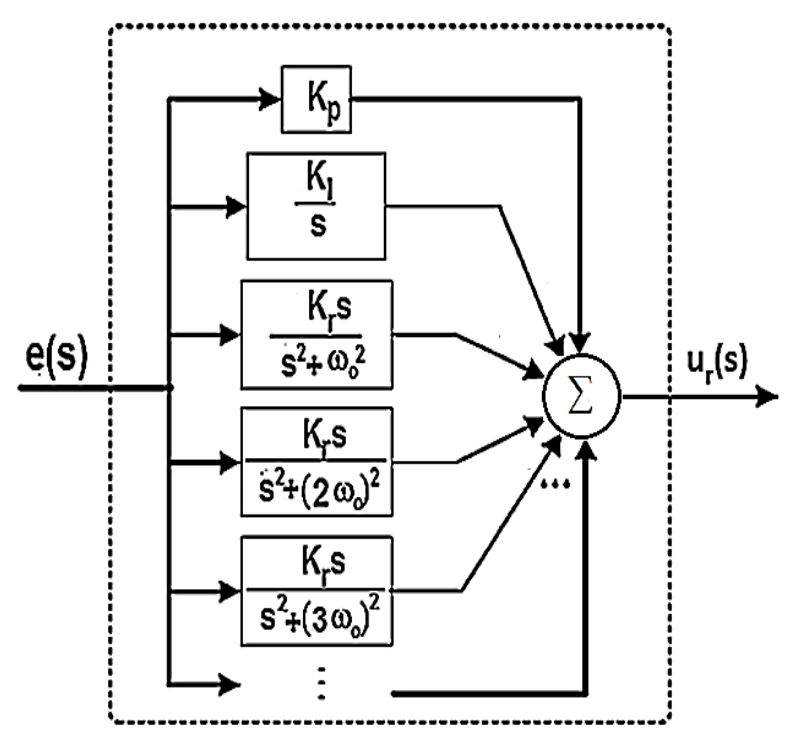

Figure 5: Equivalent form of RC controller

Hence, Figure 5 shows that the transfer function of the repetitive scheme [right-hand side of equation (61)] can be considered as a bank of infinite number of resonant filters, all connected in parallel.

\section{B. Current Controller}

The objectives of the current controller are: to construct the reference currents by using Phase Locked Loop (PLL) technique, and to achieve good tracking between the actual and the 
reference currents by employing proportional controller only. The components of the current controller will be discussed in details in the following sections.

\section{- Enhanced Phase Locked Loop (EPLL):}

The EPLL enhances the standard PLL by removing its main drawback that is the presence of double-frequency errors. It achieves this task by means of estimating the amplitude of the input signal. Thus, in addition to removing the ripples, the EPLL provides an estimate of the input signal magnitude and a filtered version of the input signal. This makes the EPLL function as a filter and as a controller too. The block diagram of the EPLL is shown in Figure 6. The EPLL comprises a PLL (shown in the box on the bottom of Figure 6) and also a branch that generates a signal y that is the filtered version of the input signal $u$. Thus, $Y$ estimates the peak value of the input signal, and $\phi$ estimates its phase angle. The frequency is estimated at $\omega$. The signal $\mathrm{S}$ is unity sinusoidal signal in phase with the input signal, and this represents a stable synchronizing reference. [12]

Assume $(\mathrm{u}=\mathrm{U} \sin \theta$, where $\theta=\omega \mathrm{t})$ and $(\mathrm{y}=\mathrm{Y} \sin \phi)$. Obviously, when $(\mathrm{Y}=\mathrm{U}$ and $\phi=\theta)$, the EPLL is in a steady situation, and the error signal $\mathrm{e}=(\mathrm{u}-\mathrm{y})$ is zero. If this steady situation is stable, then it means that the EPLL approaches the correct solution. For $(\mathrm{u}=\mathrm{U} \sin \theta)$ and $(\mathrm{y}=$ $\mathrm{Y} \sin \phi)$, the error signal is $(\mathrm{e}=\mathrm{u}-\mathrm{y})=(\mathrm{U}$ $\sin \theta-Y \sin \phi)$. The output of phase detector (PD) (the multiplier in PLL) in Figure 6 is equal to

$$
\begin{gathered}
\mathrm{z}=\mathrm{e} \cos \phi=(\mathrm{U} \sin \theta-\mathrm{Y} \sin \phi) \cos \phi \\
\mathrm{z}=\frac{\mathrm{U}}{2} \sin (\theta-\phi)+ \\
\underbrace{\frac{\mathrm{U}}{2} \sin (\theta+\phi)-\frac{\mathrm{Y}}{2} \sin 2 \phi}_{\text {high-frequency }}
\end{gathered}
$$

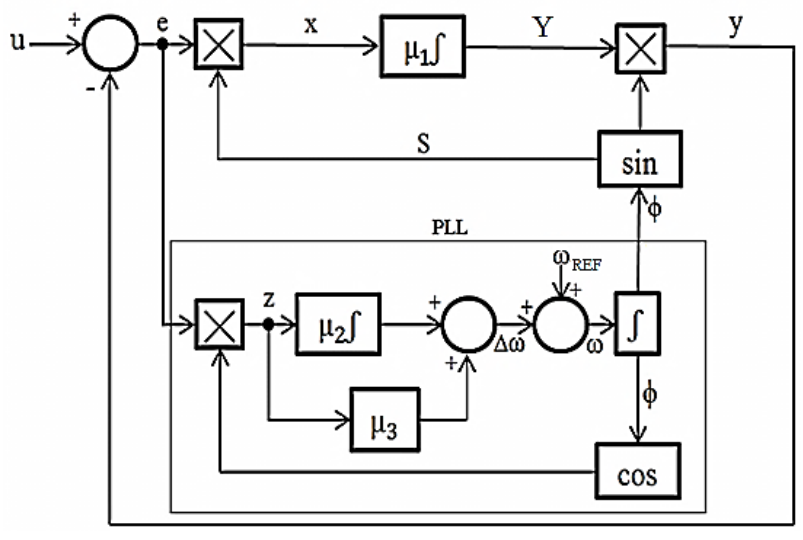

Figure 6: EPLL block diagram

Assuming that the steady situation (i.e., $\mathrm{Y}=\mathrm{U}$ and $\phi=\theta$ ) is stable, the highfrequency term approaches zero as the system approaches to the steady situation. This means that the high- or doublefrequency term keeps being removed from the loop and the frequency and phase angle estimations will carry no double-frequency ripple as they approach their steady values. The output of the top multiplier in Figure 6 is equal to

$$
\begin{aligned}
& \mathrm{X}=\mathrm{e} \sin \phi=(\mathrm{U} \sin \theta-\mathrm{Y} \sin \phi) \sin \phi \\
& \mathrm{X}=\quad \frac{\mathrm{U}}{2} \cos (\theta-\phi)-\frac{\mathrm{Y}}{2}+ \\
& \underbrace{\frac{\mathrm{Y}}{2} \cos (2 \phi)-\frac{\mathrm{U}}{2} \cos (\theta+\phi)}_{\text {high-frequency }}
\end{aligned}
$$

As the system approaches the steady condition, the high frequency term approaches zero. Therefore, there will be no double-frequency ripple on the estimated peak value.The selection of the parameters in Figure $6(\mu 1, \mu 2$, and $\mu 3)$ depends on the following observation:

- Increasing the value of $\mu_{1}$ will increase the speed of estimating of the magnitude. However, it creates oscillations in the response. There is a tradeoff between speed and accuracy (or smoothness).

- Decreasing $\mu_{1}, \mu_{2}$, and $\mu_{3}$ yield an estimation of the peak, and phase which is insensitive/robust to theundesirable variations and noise in the input signal. 
Finally, the output of the EPLL(S in Figure 6) will be pure unit sinusoidal and synchronized with the voltage in each phase, therefore the reference currents are:

$$
\begin{aligned}
& \mathrm{i}_{\mathrm{r} 1}=\mathrm{I}_{\text {MAX }} \sin (\omega \mathrm{t}) \\
& \mathrm{i}_{\mathrm{r} 2}=\mathrm{I}_{\text {MAX }} \sin (\omega \mathrm{t}-120) \\
& \mathrm{i}_{\mathrm{r} 3}=\mathrm{I}_{\text {MAX }} \sin (\omega \mathrm{t}+120)
\end{aligned}
$$

\section{- Proportional Controller:}

Theblock diagram of the current control loop shown in Figure 7, gains and time constants associated with various elements of the this block diagram are as follow

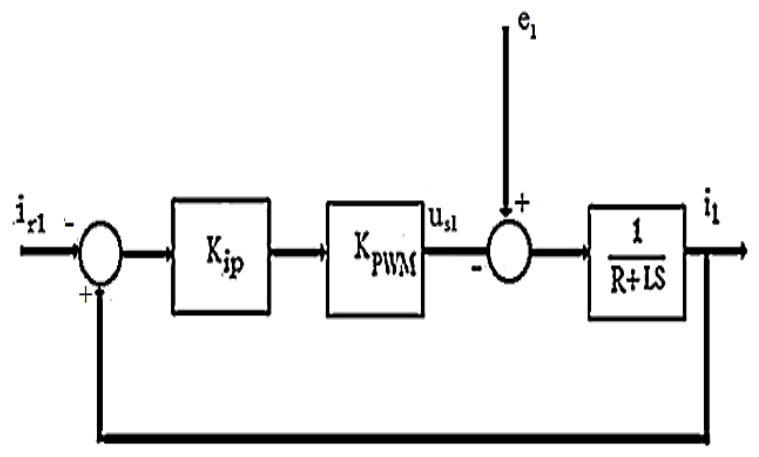

Figure 7: Block diagram of the current control loop.

$\mathrm{e}_{1} \quad$ source voltage

$\mathrm{u}_{\mathrm{s} 1} \quad$ converter input voltage

$\mathrm{K}_{\mathrm{ip}} \quad$ gain of the $\mathrm{P}$ controller

$\mathrm{K}_{\mathrm{PWM}}$ gain of the PWM block

$\mathrm{T}_{\mathrm{RL}}$ time constant of the plant $=\frac{\mathrm{L}}{\mathrm{R}}$

$\mathrm{K}_{\mathrm{RL}} \quad$ gain of the plant $=\frac{1}{\mathrm{R}}$

$\mathrm{i}_{1} \quad$ line current

$\mathrm{i}_{\mathrm{r} 1} \quad$ reference current

Forward transfer function $=\frac{\mathrm{K}_{\mathrm{ip}} \mathrm{K}_{\mathrm{PWM}} \mathrm{K}_{\mathrm{RL}}}{1+\mathrm{ST}_{\mathrm{RL}}}$

The closed loop transfer function is

$$
=\frac{\frac{K_{i p} K_{P W M} K_{R L}}{1+S T_{R L}}}{1+\frac{K_{i p} K_{P W M} K_{R L}}{1+S T_{R L}}}
$$

$$
\begin{aligned}
& =\frac{\frac{\mathrm{K}_{\mathrm{ip}} \mathrm{K}_{\mathrm{PWM}} \mathrm{K}_{\mathrm{RL}}}{1+\mathrm{ST}_{\mathrm{RL}}}}{\frac{1+\mathrm{ST}_{\mathrm{RL}}+\mathrm{K}_{\mathrm{ip}} \mathrm{K}_{\mathrm{PWM}} \mathrm{K}_{\mathrm{RL}}}{1+\mathrm{ST}_{\mathrm{RL}}}} \\
& =\frac{\mathrm{K}_{\mathrm{ip}} \mathrm{K}_{\mathrm{PWM}} \mathrm{K}_{\mathrm{RL}}}{\mathrm{ST}_{\mathrm{RL}}+\mathrm{K}_{\mathrm{ip}} \mathrm{K}_{\mathrm{PWM}} \mathrm{K}_{\mathrm{RL}}+1}
\end{aligned}
$$

$\mathrm{K}_{\mathrm{ip}} \mathrm{K}_{\mathrm{PWM}} \mathrm{K}_{\mathrm{RL}}>>1$, so the closed loop transfer function becomes

$\frac{\mathrm{i}_{1}}{\mathrm{i}_{\mathrm{r} 1}}=\frac{1}{1+\mathrm{T}_{\mathrm{e}} \mathrm{S}}$

(67)

Where $\mathrm{T}_{\mathrm{e}}=\frac{\mathrm{T}_{\mathrm{RL}}}{\mathrm{K}_{\mathrm{ip}} \mathrm{K}_{\mathrm{PWM}} \mathrm{K}_{\mathrm{RL}}}$

\section{SIMULATION RESULTS}

The operation of the three-phase PWM boost-type rectifier under severe unbalanced and distorted operating conditions has been simulated in MATLAB Simulink by using SimPowerSystems toolbox. Five different cases have been selected to verify feasibility and performance of the new control method (with RC). The converter operates at near unity power factor with a stable behavior in spite of level of imbalance and distortion of the input conditions. The main electrical parameters of the power circuit and control data are given in Table 1.

Table 1 : Electrical parameters of power circuit and control data

\begin{tabular}{|c|c|c|c|}
\hline $\begin{array}{c}\text { Switching } \\
\text { Frequency }\left(\mathrm{F}_{\mathrm{S}}\right)\end{array}$ & $10000 \mathrm{~Hz}$ & $\begin{array}{c}\text { Output dc } \\
\text { voltage } \\
\mathrm{V}_{\mathrm{o}}\end{array}$ & $300 \mathrm{~V}$ \\
\hline Resistance of & $0.01 \Omega$ & $\begin{array}{c}\text { Nominal } \\
\text { input } \\
\text { voltage } \\
\left.\text { reactor( } \mathrm{R}_{\mathrm{L}}\right)\end{array}$ & $120 \mathrm{~V}$ \\
\hline $\begin{array}{c}\text { Inductance of } \\
\text { reactors (L) }\end{array}$ & $5 \mathrm{mH}$ & $\begin{array}{c}\text { supply } \\
\text { frequency }\end{array}$ & $50 \mathrm{~Hz}$ \\
\hline $\begin{array}{c}\text { dc-bus } \\
\text { capacitor }(\mathrm{C})\end{array}$ & $480 \mu \mathrm{F}$ & $\mathrm{K}_{\mathrm{ip}}$ & 133 \\
\hline $\begin{array}{c}\text { Load } \\
\text { resistance } \mathrm{R}_{\mathrm{o}}\end{array}$ & $100 \Omega$ & $\mu_{1}, \mu_{2}, \mu_{3}$ & $18,0.1,0.1$ \\
\hline
\end{tabular}


The cases are:

\section{CASE 1}

In this case, the operation of the three-phase PWM boost rectifier is simulated under balanced input voltages condition. Figure 8 shows three-phase input voltages condition of this case, where $\mathrm{Em}_{1}=\mathrm{Em}_{2}=\mathrm{Em}_{3}=120 \mathrm{~V}$. Figure 9 show the steady-state three-phase input currents and Figure 10 shows the output dc voltage when using RC.

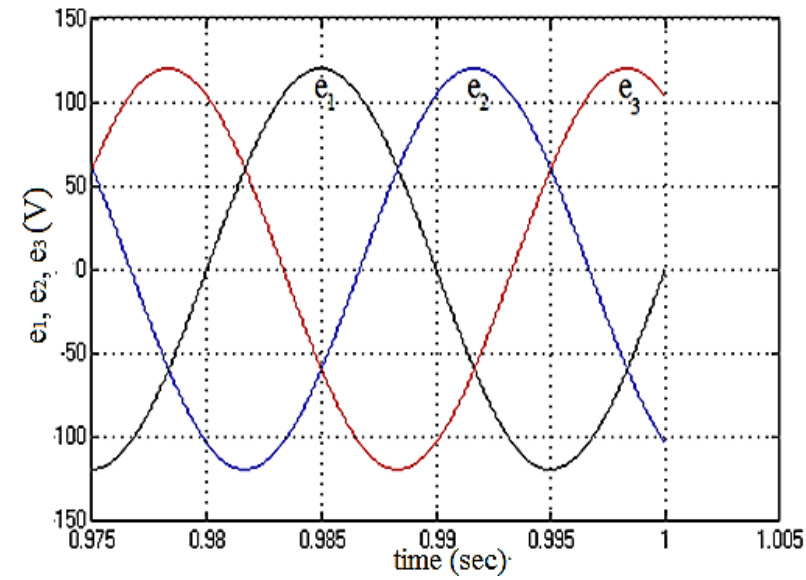

Figure 8: Input voltages of case1

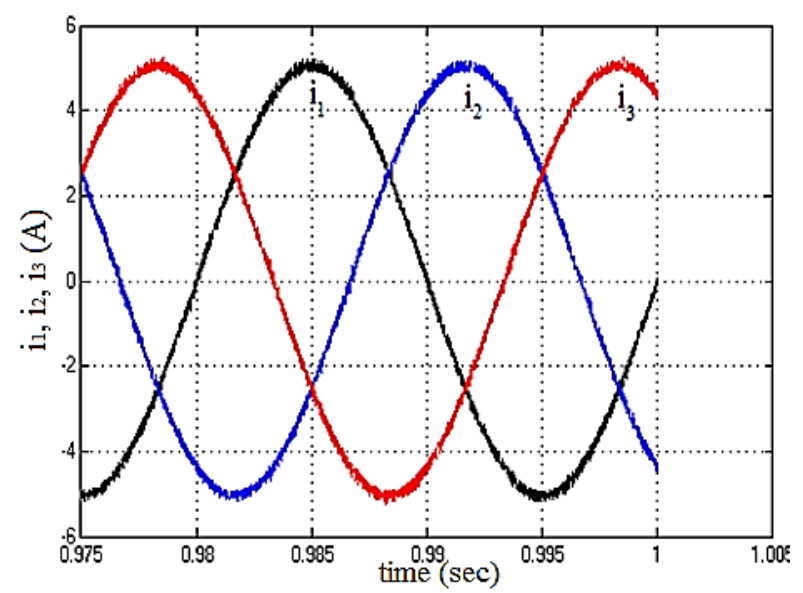

Figure 9: Input line currents when using repetitive controller $(\mathrm{RC})$ in case 1

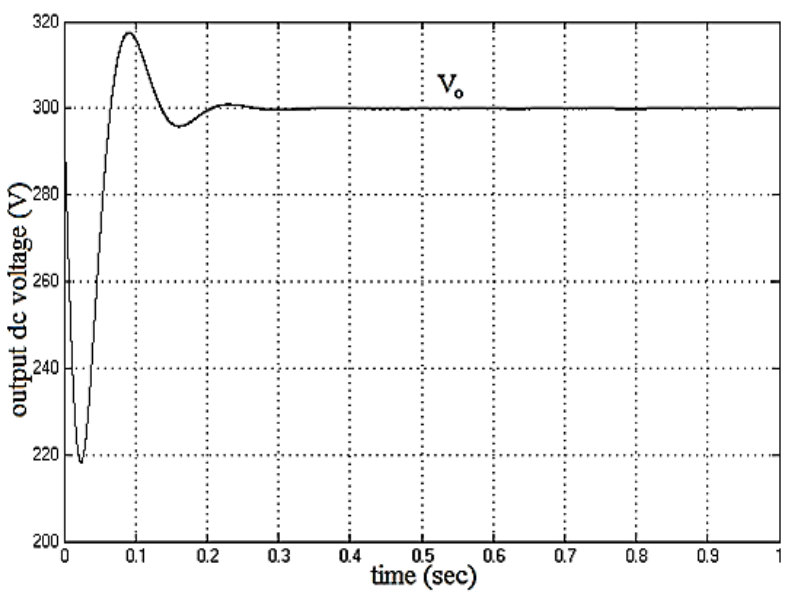

Figure 10: Output de voltage when using $\mathrm{RC}$ in case 1

\section{CASE 2}

If the input voltages are $\mathrm{Em}_{1}=190 \mathrm{~V}, \mathrm{Em}_{2}=120 \mathrm{~V}$, and $\mathrm{Em}_{3}=70 \mathrm{~V}$ as shown in Figure 11, then the input currents obtained when using RC are shown in Figure 12. The negative sequence current in Figure 12 is $0.02705 \mathrm{~A}$, and the third order harmonic currents in each phase are $0.01 \mathrm{~A}, 0 \mathrm{~A}$, and $0.01 \mathrm{~A}$, while the $\mathrm{THD}_{\mathrm{s}}$ are $1.96 \%, 1.98 \%$, and $2.04 \%$ respectively.

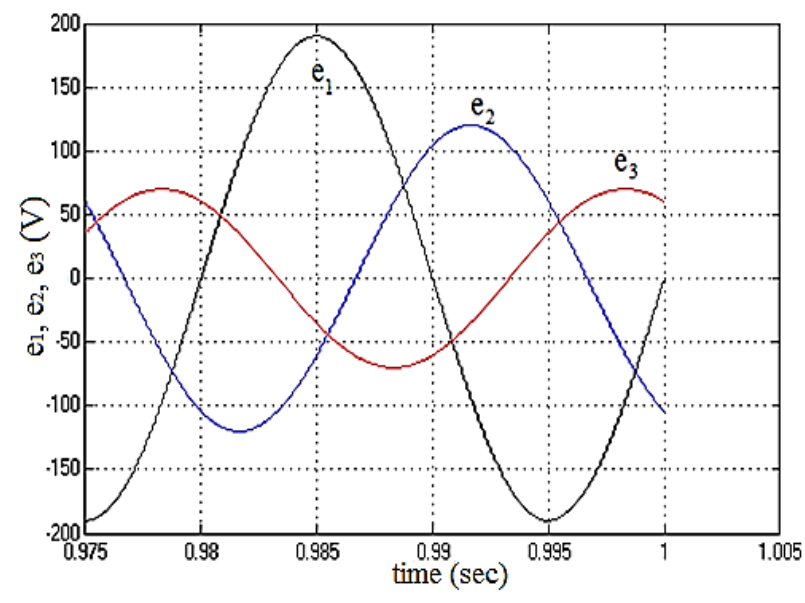

Figure 11: Unbalanced input voltages of case2 


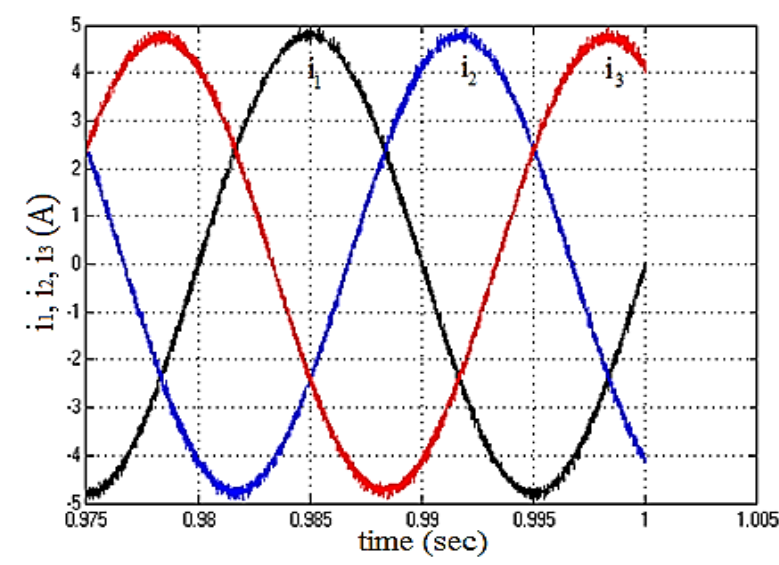

Figure 12: Input currents obtained when using $\mathrm{RC}$ in case 2

Figure 13 shows the output dc voltage of this case, the second order harmonic voltage is equal to $(5.62 \mathrm{~V}$ peakto-peak (P.P)) when RC is used.The power factor obtained for this case is 0.9874 .

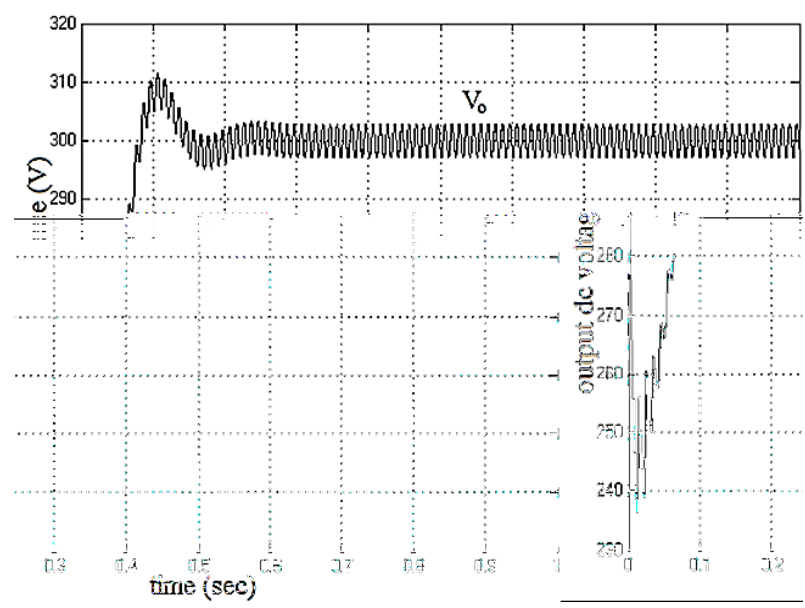

Figure 13: Output de voltage obtain when using $\mathrm{RC}$ in case 2

\section{CASE 3:}

In this case, a $5^{\text {th }}$ order harmonic of $25 \%$ distorts unbalanced input voltages $\left(\mathrm{Em}_{1}=157 \mathrm{~V}, \mathrm{Em}_{2}=120 \mathrm{~V}\right.$, and $\left.\mathrm{Em}_{3}=85 \mathrm{~V}\right)$. Figure 14 shows the input voltages of this case, while the input currents obtained when using $\mathrm{RC}$ in this case are shown in Figure 15. Figure 16 shows the output dc voltage.

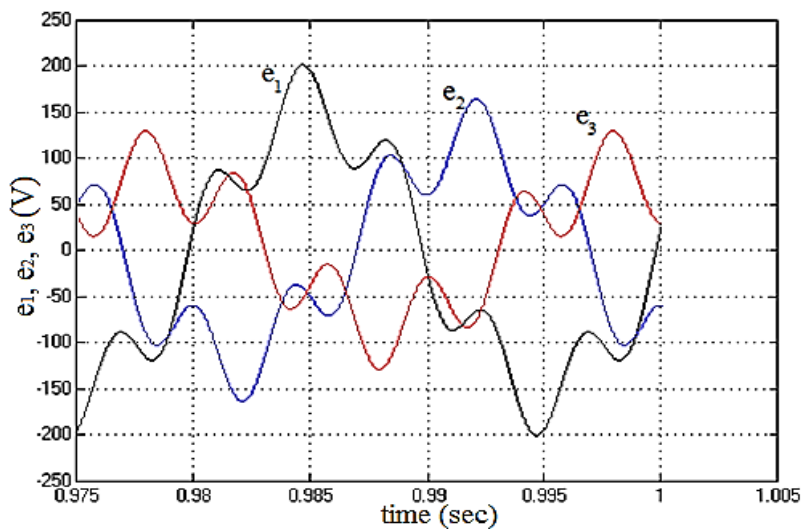

Figure 14: Input voltages of case3

The $\mathrm{THD}_{\mathrm{s}}$ for the input currents are $1.94 \%, 2.03 \%$, and $2.15 \%$ respectively, while the $3^{\text {rd }}$ order harmonics are $0 \mathrm{~A}$, $0.01 \mathrm{~A}$, and $0.01 \mathrm{~A}$. The $5^{\text {th }}$ order harmonics in these currents are $0.02 \mathrm{~A}, 0.03 \mathrm{~A}$, and $0.04 \mathrm{~A}$ respectively. The second order harmonic in the output dc voltage is $(3.54 \mathrm{~V}$ P.P). The power factor for this case is 0.912 .

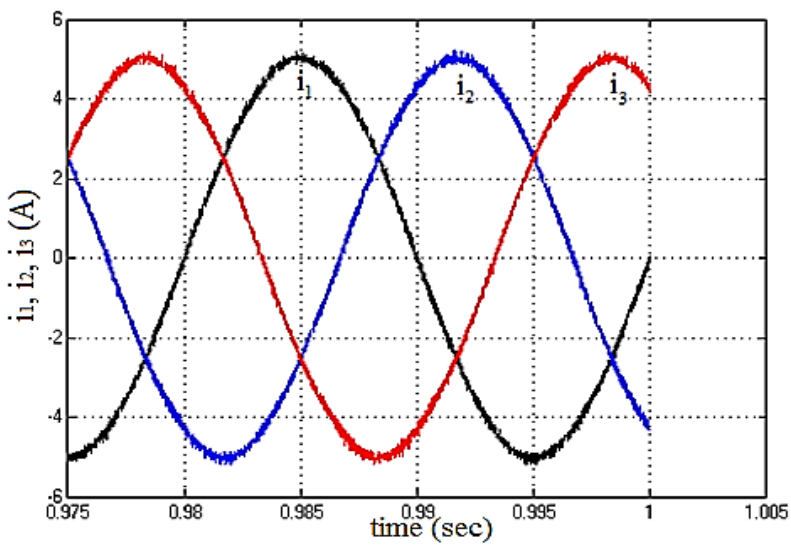

Figure 15: Input line currents obtained when using RC in case 3.

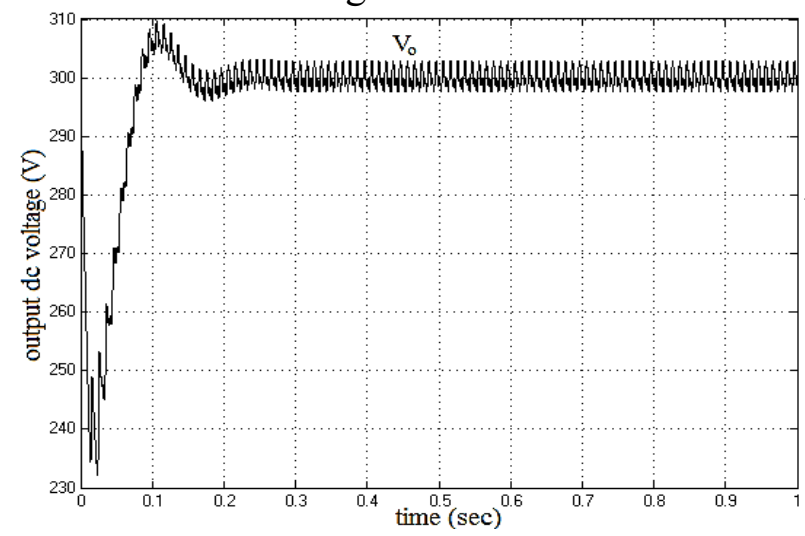

Figure 16: Output dc voltage obtained when using RC in case3. 


\section{CASE 4:}

In this case, a $7^{\text {th }}$ order harmonic of $25 \%$ distorts unbalanced input voltages $\left(\mathrm{Em}_{1}=157 \mathrm{~V}, \mathrm{Em}_{2}=120 \mathrm{~V}\right.$, and $\left.\quad \mathrm{Em}_{3}=85 \mathrm{~V}\right)$. Figure 17 shows the waveforms of the input voltages of this case. Figure 18 shows the input line currents, while Figure 19 shows the output de voltage.

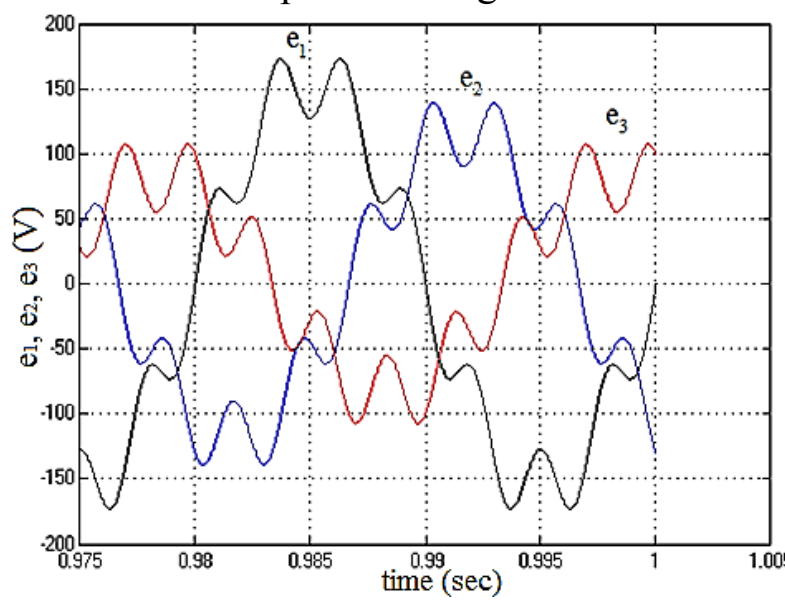

Figure 17: Waveforms of the input voltages of case 4

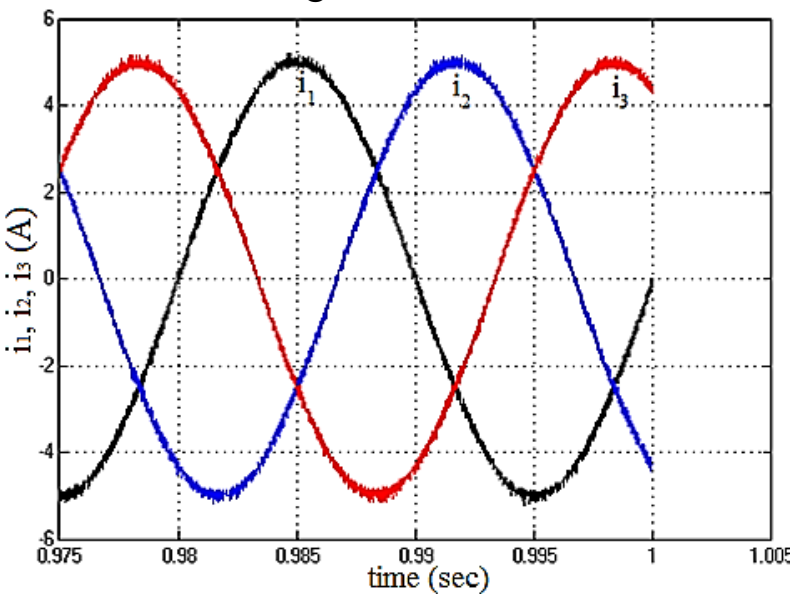

Figure 18: Input currents obtained when using $\mathrm{RC}$ in case 4

The $\mathrm{THD}_{\mathrm{s}}$ for the input currents in Figure 18 are $1.97 \%, 1.97 \%$, and $2 \%$ for the three phases respectively, while the $7^{\text {th }}$ order harmonic is $0.02 \mathrm{~A}$ for each phase. The obtained power factor for this case is 0.9573 .

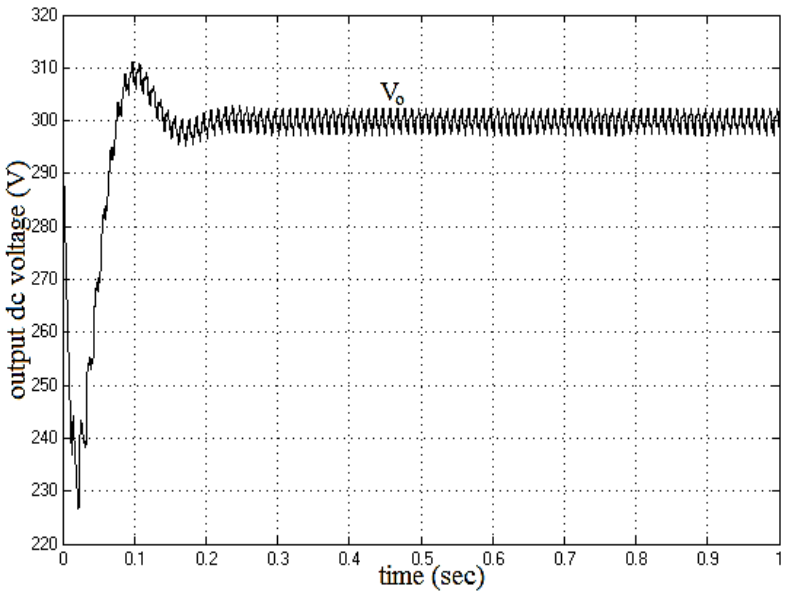

Figure 19: Output de voltage obtain when using RC in case 4

\section{CASE 5:}

In this case, unbalanced input voltages $\mathrm{Em}_{1}=157 \mathrm{~V}, \mathrm{Em}_{2}=120 \mathrm{~V}$, and $\mathrm{Em}_{3}=85 \mathrm{~V}$ are considered, these voltages are distorted by a $5^{\text {th }}$ harmonic of $20 \%$ and a $7^{\text {th }}$ harmonic of $20 \%$. Figure 20 shows the waveforms of the input voltages.

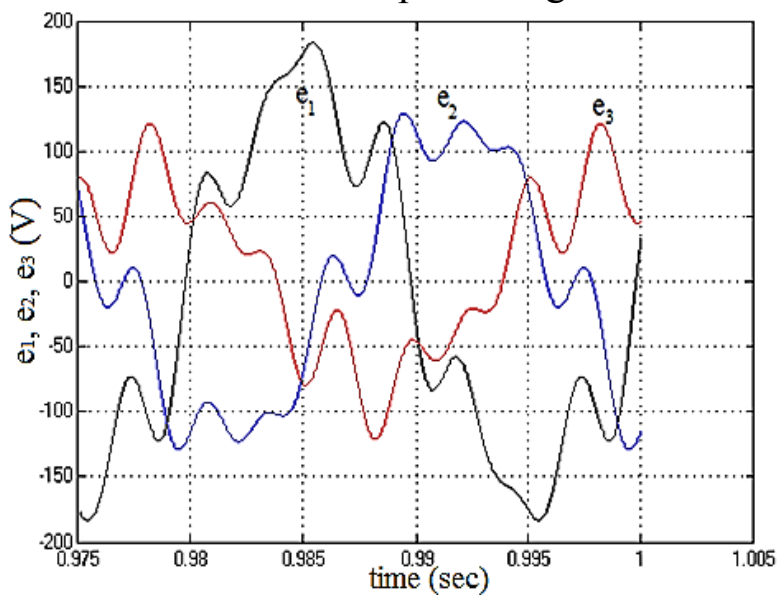

Figure 20: Waveforms of the input voltages of case 5

Figure 21 shows the input line currents obtained when using RC. The $\mathrm{THD}_{\mathrm{s}}$ for these currents are $1.99 \%, 1.89 \%$, and $2.07 \%$ respectively, while the third order harmonic in each phase current is $0 \mathrm{~A}$. Figure 22 shows the output dc voltage when using $\mathrm{RC}$, the second order harmonic is (5V P.P.). The power factor obtained for this case is 0.9036 . 


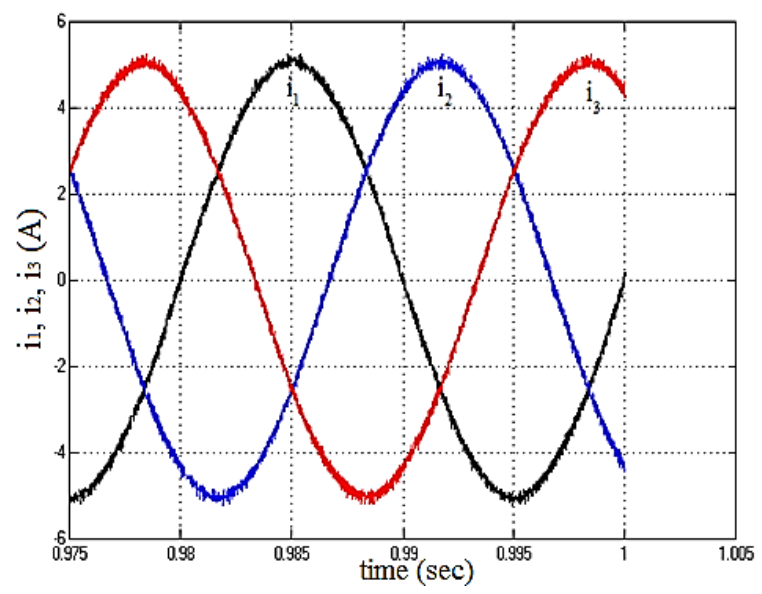

Figure 21: Input line currents obtained when using $\mathrm{RC}$ in case 5

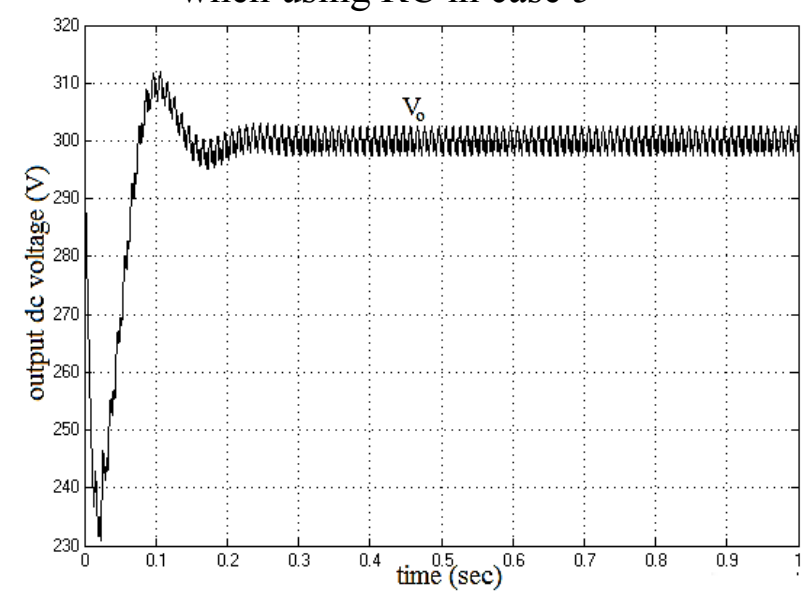

Figure 22: Output dc voltage obtained when using $\mathrm{RC}$ in case 5

For all cases, it is noticed that the output dc voltage requires $140 \mathrm{~ms}$ (settling time) to be stable at the beginning of the operation within a variation of $6 \%$. Figure 23 shows the dc link voltage and the ac line current with using RC when the load is changed from $100 \Omega$ to $50 \Omega$ at $0.6 \mathrm{sec}$ and back to $100 \Omega$ at $0.8 \mathrm{sec}$ from starting time.In increasing the load,it is clear that an oscillation in the dc link voltage is occurred within $8 \%$ (decrease in the output dc voltage), and it is damped after $85 \mathrm{msec}$ from the instant of increasing the load. The ac line current (increased from 5A to 10A) also reaches to the steady state (stable at $10 \mathrm{~A}$ ) in two cycles, around $40 \mathrm{~ms}$. When the load returns to $100 \Omega$, the oscillation in the output dc voltage is within $9 \%$ (increase in the output dc voltage) and this oscillation is damped after $130 \mathrm{msec}$.

The ac input line current reaches to the steady state (stable at $5 \mathrm{~A}$ ) in six cycles, around $120 \mathrm{~ms}$.

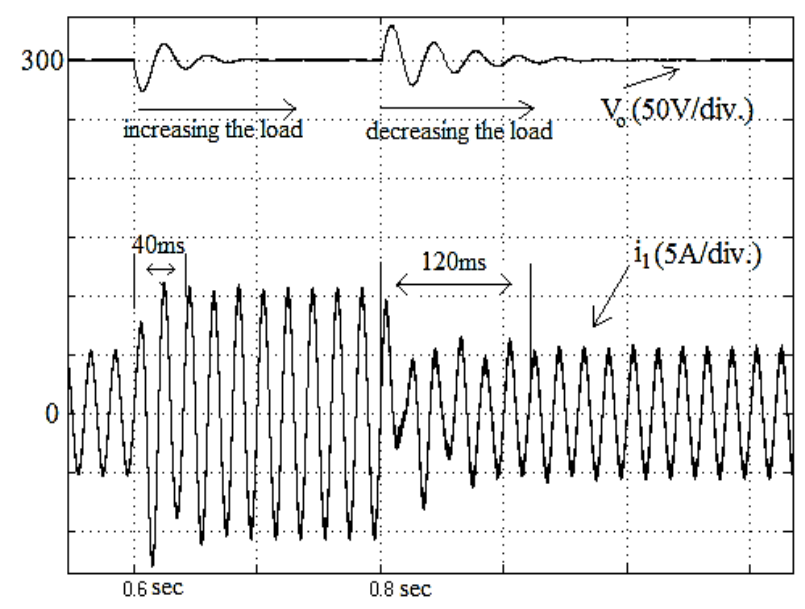

Figure 23: Simulation results of the output dc voltage and ac line current when using $\mathrm{RC}$ under changing the load

All the results of the output dc voltage that are mentioned above show excellent voltage regulation at steady state and transient conditions. The output dc voltage tracks the reference dc voltage with small ripple (less than 6V P.P) at steady state. While the oscillation in the output dc voltage is no more than $6 \%$ for transient condition (step change in load). Now, the conventional control method (Proportional Integral (PI) controller with a Low Pass Filter (LPF)) is compared with the RC under supplying unbalanced input voltages (case2) and under changing the load. The cutoff frequency of LPF is $50 \mathrm{~Hz}$ and the parameters of the PI controller are $\mathrm{K}_{\mathrm{vp}}=1$ and $\mathrm{K}_{\mathrm{vi}}=66$, where $\mathrm{K}_{\mathrm{vp}}$ is the proportional gain and $\mathrm{K}_{\mathrm{vi}}$ is the integral gain of the voltage controller.

Figure 24 shows the de current $\mathrm{I}_{\mathrm{MAX}}$ when the input supply voltages are $\mathrm{Em}_{1}=190 \mathrm{~V}, \mathrm{Em}_{2}=120 \mathrm{~V}$, and $\mathrm{Em}_{3}=70 \mathrm{~V}$ as shown in Figure 11 (case2). 


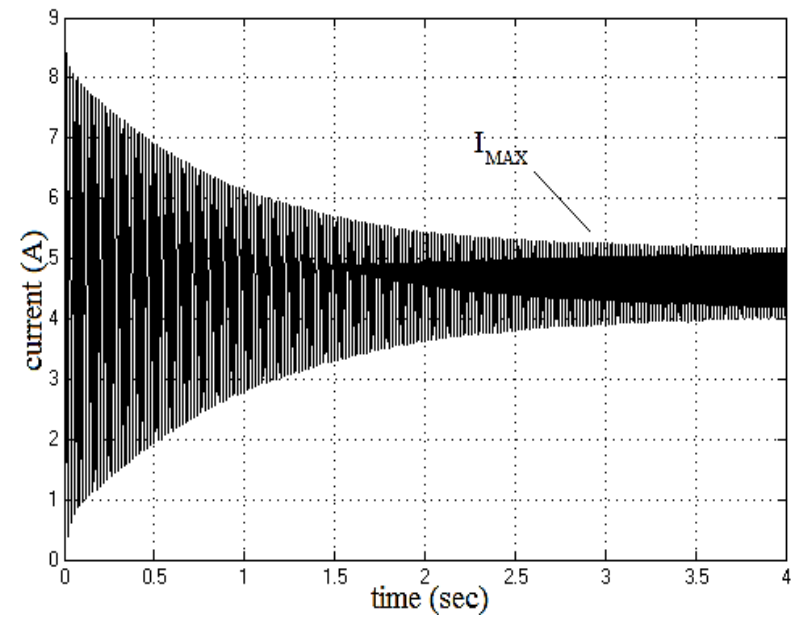

Figure 24: $\mathrm{I}_{\mathrm{MAX}}$ obtained when using the conventional method

The second order harmonic in this current is $0.5 \mathrm{~A}$ (1A P.P), this leads for appearing a third order harmonic in the input currents and makes THDs for these currents are higher than 5\%. Figure 25 shows the waveforms of the three-phase input currents with using the conventional controlled method and when the input voltages in Figure 11 are used.

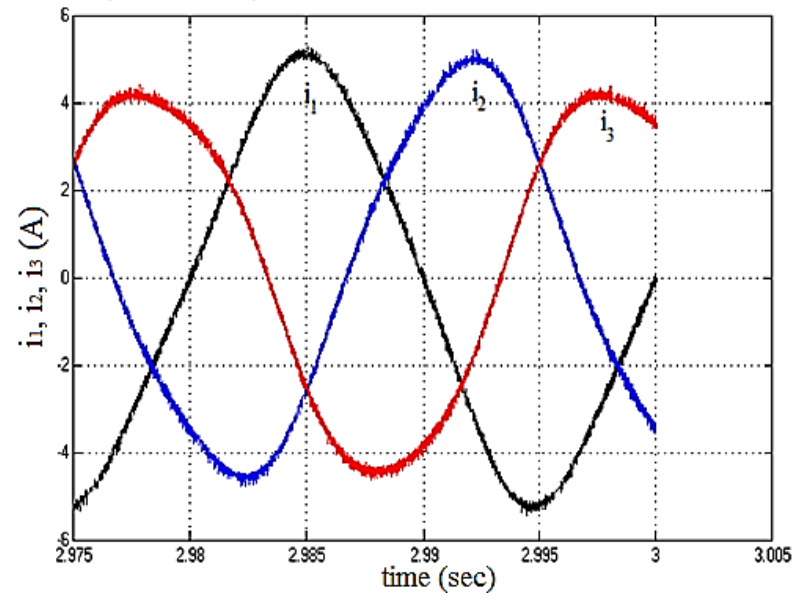

Figure 25: Input currents obtained when using the conventional method and under unbalanced supply voltage level in case 2

Figure 26 shows the output dc voltage $\mathrm{V}_{\mathrm{o}}$, the second order harmonic in this voltage is $8.6 \mathrm{~V}$ (P.P). This Figure shows that the output dc voltage enters the steady state after $2.6 \mathrm{sec}$ from starting time of operation.

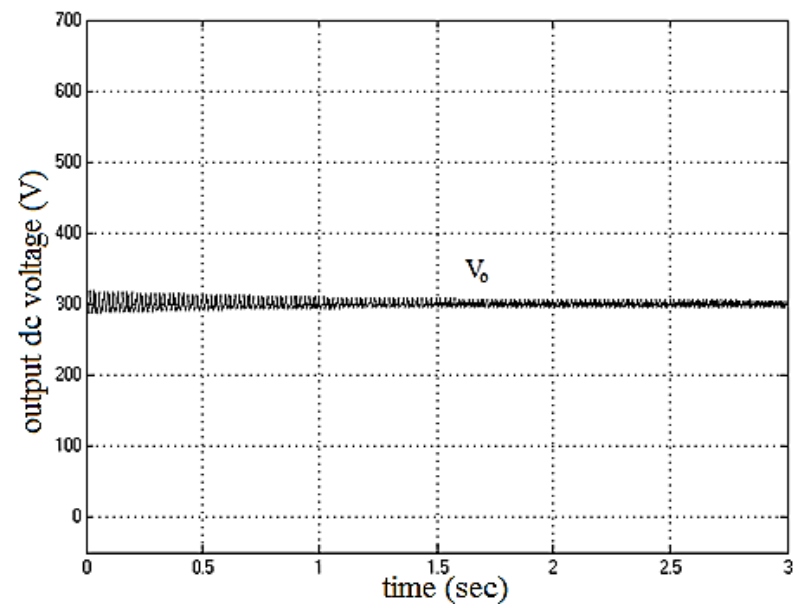

Figure26: Output dc voltage obtained when using the conventional method

Figure 27 shows the ac line current and the output dc voltage when using LPF with PI controller under load change condition. So that when the load is increased at $0.6 \mathrm{sec}$ from starting time, the ac line current requires six cycles $(120 \mathrm{~ms})$ to reach the steady state. An oscillation occurs at the output dc voltage and this oscillation is damped after $130 \mathrm{msec}$ from the instant of increasing the load. The load returns to $100 \Omega$ at $0.8 \mathrm{sec}$ from starting the operation, this causes an oscillation in the output de voltage but this oscillation is damped after $160 \mathrm{~ms}$. While the ac line current requires ten cycles to be stable, around $200 \mathrm{~ms}$.

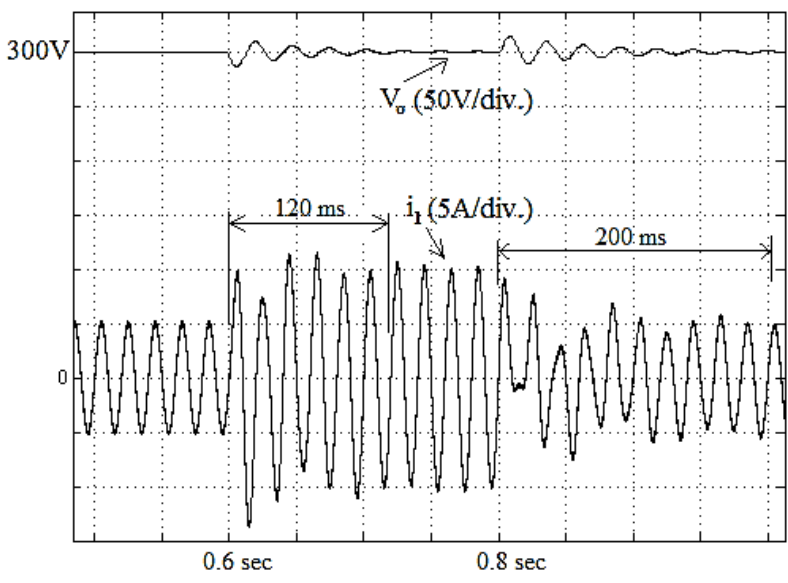

Figure 27: Simulation results of dc voltage and ac line current when using LPF and PI controller under changing the load 
Table 2 shows the ripple in the output dc voltage, the negative sequence current, and the third order harmonic in the input line currents when RC and LPF with PI controller are used. Table 3 shows THDs when using the conventional method and Table 4 shows THDs when using the proposed method.

Table 2: Third order harmonics, output ripple, and negative sequence current obtained for both conventional and $\mathrm{RC}$ methods when the level voltages in case 2

\begin{tabular}{|c|c|c|c|c|c|c|}
\hline & \multicolumn{3}{|c|}{$\mathrm{RC}$} & \multicolumn{3}{|c|}{$\begin{array}{c}\text { Conventional } \\
\text { method }\end{array}$} \\
\hline & $\mathrm{i}_{1}$ & $\mathrm{i}_{2}$ & $\mathrm{i}_{3}$ & $\mathrm{i}_{1}$ & $\mathrm{i}_{2}$ & $\mathrm{i}_{3}$ \\
\hline $\begin{array}{c}\text { 3rd } \\
\text { order(A) }\end{array}$ & $\begin{array}{c}0.0 \\
1 \\
\end{array}$ & 0 & $\begin{array}{c}0.0 \\
1 \\
\end{array}$ & 0.25 & 0.25 & 0.25 \\
\hline Ripple(P.P) & \multicolumn{3}{|c|}{$5.62 \mathrm{~V}$} & \multicolumn{3}{|c|}{$8.6 \mathrm{~V}$} \\
\hline $\begin{array}{l}\text { Negative } \\
\text { sequence } \\
\text { current (A) }\end{array}$ & \multicolumn{3}{|c|}{0.026} & \multicolumn{3}{|c|}{0.271} \\
\hline
\end{tabular}

Table 3 : THDs obtained when using the conventional method

\begin{tabular}{|l|c|c|c|}
\hline \multicolumn{4}{|c|}{ Conventional method } \\
\hline & $\begin{array}{c}\text { THD\% } \\
\text { of phase1 }\end{array}$ & $\begin{array}{c}\text { THD\% } \\
\text { of phase } 2\end{array}$ & $\begin{array}{c}\text { THD } \% \\
\text { of phase3 }\end{array}$ \\
\hline CASE1 & 1.78 & 1.75 & 1.83 \\
\hline CASE2 & 6 & 6.13 & 6.25 \\
\hline CASE3 & 3.57 & 2.93 & 3.27 \\
\hline CASE4 & 3.64 & 3.18 & 3.91 \\
\hline CASE5 & 4.11 & 3.58 & 3.98 \\
\hline
\end{tabular}

Table 4 : THDs obtained when using the proposed method

\begin{tabular}{|l|c|c|c|}
\hline \multicolumn{4}{|c|}{ Proposed method } \\
\hline & $\begin{array}{c}\text { THD } \% \\
\text { of phase1 }\end{array}$ & $\begin{array}{c}\text { THD\% } \\
\text { of phase2 }\end{array}$ & $\begin{array}{c}\text { THD } \% \\
\text { of phase3 }\end{array}$ \\
\hline CASE1 & 1.93 & 1.93 & 2.05 \\
\hline CASE2 & 1.96 & 2.01 & 1.98 \\
\hline CASE3 & 1.94 & 2.03 & 2.15 \\
\hline CASE4 & 1.97 & 1.97 & 2 \\
\hline CASE5 & 1.99 & 1.89 & 2.07 \\
\hline
\end{tabular}

It can be seen from these tables that when using the proposed method (RC), the $\mathrm{THD}_{\mathrm{s}}$ in the input line currents, the negative sequence currents, and the second order harmonic in the output dc voltage are less, in comparing to their values when using the conventional method (LPF with PI controller).

Figure 28 shows the output dc voltage when using the proposed method. In this Figure, the reference output dc voltage is changed from $300 \mathrm{~V}$ to $400 \mathrm{~V}$ at $0.3 \mathrm{sec}$ from starting time and from $400 \mathrm{~V}$ to $350 \mathrm{~V}$ at $0.6 \mathrm{sec}$.

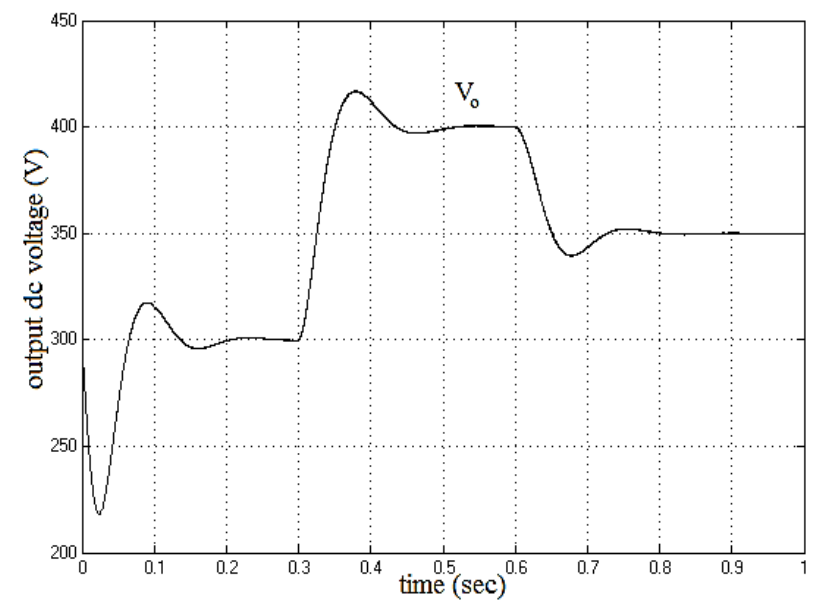

Figure 28: changing the output reference dc voltage when using the proposed method

Figure 29 shows the changing of the reference output dc voltage when using the conventional method. 


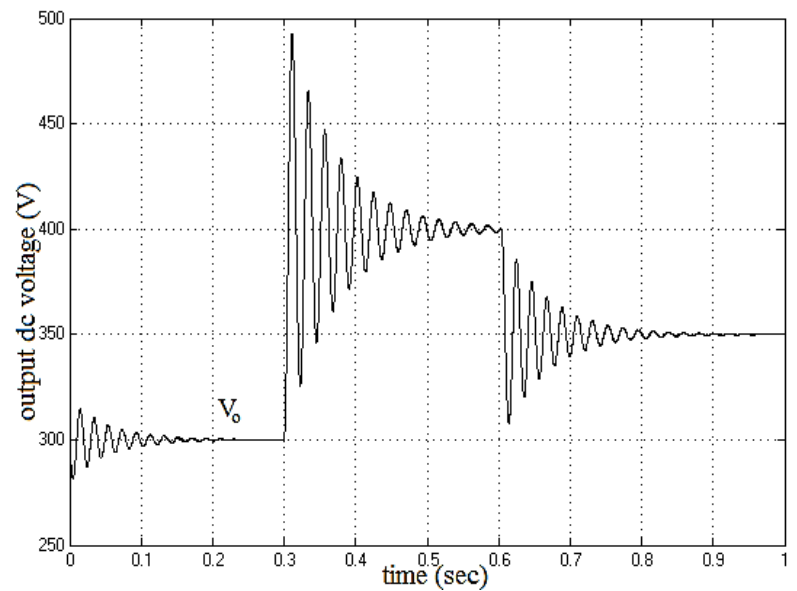

Figure 29: changing the output reference dc voltage when using the conventional method

From Figures 28 and 29, the oscillation in the output dc voltage within $6 \%$ when using the proposed method, while $28 \%$ when using the conventional method. Therefore, the proposed method produces excellent performance with using small value of the output capacitor and producing excellent input-output harmonic elimination. To improve the performance of the conventional method, the value of the output capacitor must be larger.

Finally, Figure 30 and Figure 31 show three-phase input line currents and the output dc voltage with using $\mathrm{RC}$ when inductor $(3 \mathrm{mH})$ is added to the resistive load which its value is $100 \Omega$ under supplying unbalancedinputvoltages in case 2.

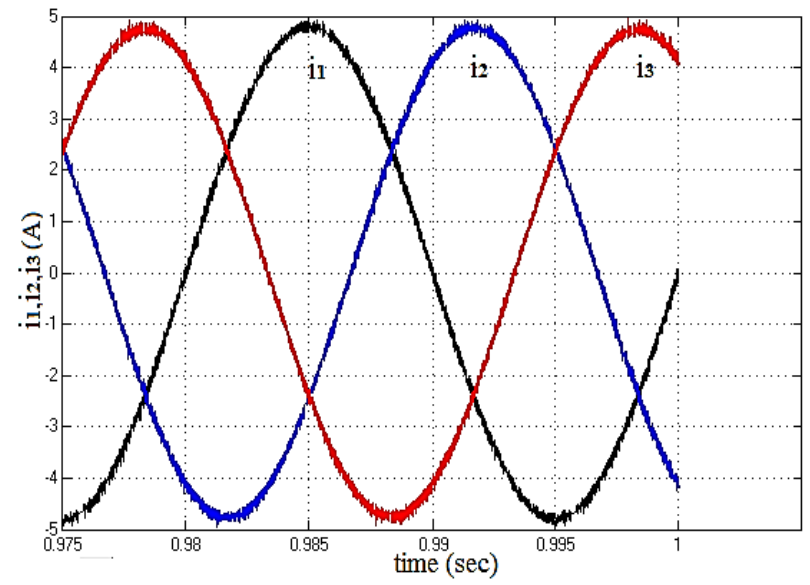

Figure 30: Input currents obtained when using the proposed method and under unbalanced supply voltage level in case2

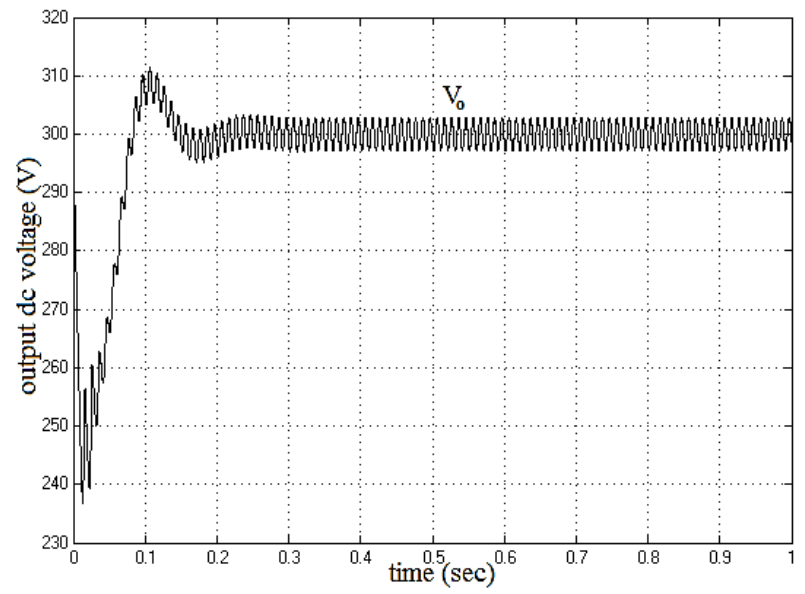

Figure 31: Output de voltage obtained when using RC

THDs for the input line currents in Figure 30 are $1.99 \%, 2 \%$, and $2.05 \%$. While the power factor is 0.9915 and the second order harmonic in the output dc voltage in Figure 31 is $5.64 \mathrm{~V}$. So the performance of PWM rectifier when using $\mathrm{RC}$ is the same with and without adding inductor $(3 \mathrm{mH})$ to the resistive load $(100 \Omega)$.

\section{Conclusions}

This paper proposed a new control strategy ( $\mathrm{RC}$ is used in the voltage controller, and EPLL with proportional controller are used in the current controller) on a three-phase PWM boost rectifier, to achieve input-output harmonic reduction under different input supply voltage conditions. It is concluded from the analysis of the PWM rectifier that when the input supply voltages are unbalanced a second order harmonic appears at the output dc voltage and this result in a third order harmonic in the input currents. The performance of reduction these harmonics for both the proposed method and the conventional method is evaluated. The proposed control method (RC) uses small output capacitor, this makes the system is smaller in size, improves the transient response under the disturbances and decreases the cost of the system. In addition, the proposed method produces less second order harmonic in the reflected 
dc current $\mathrm{I}_{\mathrm{MAX}}$, this reduces the third order harmonic in the input currents and improves the $\mathrm{THD}_{\mathrm{s}}$ (less than 5\%), less third order harmonic in the input currents results in reducing the second order harmonic in the output dc voltage. While if the conventional method uses small output capacitor, $\mathrm{I}_{\mathrm{MAX}}$ has higher second order harmonic and this makes the THD higher than $5 \%$ and more harmonics will exist in the output dc voltage. Simulation results in this paper are discussed in the transient response under changing the load condition and in the steady state response under different input voltage conditions. In the steady state response, five different cases were performed to verify the feasibility of PWM rectifier with the proposed control strategy.The advantages of using the proposed method are:

1- Balanced three-phase sinusoidal input currents.

2- $\mathrm{THD}_{\mathrm{s}}$ are less than $5 \%$ for each phase.

3- The power factor is kept close to unity.

4- The output dc voltage can be regulated at any desired level.

The transient response of the input line current under changing the load when using the proposed control method requires two cycles $(40 \mathrm{~ms})$ to be stable when the load is increased from $100 \Omega$ to $50 \Omega$ and requires five cycles $(100 \mathrm{~ms})$ when the load back to $100 \Omega$. While with the conventional method, the ac line current requires six cycles $(120 \mathrm{~ms})$ to be stable when the load is increased and ten cycles (200 ms) when the load back to $100 \Omega$. Finally, the results in the steady state response and in the transient response are better when using the proposed control method.

\section{REFERENCES}

[1]. Ana Vladan Stankovic and Thomas A. Lipo "A Novel Control Method for Input Output Harmonic Elimination of the PWM Boost Type Rectifier Under Unbalanced Operating Conditions" IEEE transections on power electronics, VOL. 16, NO. 5, pp. 603-611,September2001.

[2]. Hong-seok Song and Kwanghee Nam "Dual Current Control Scheme for PWM Converter Under Unbalanced Input Voltage Conditions" IEEE transactions on industrial electronics, VOL. 46, NO. 5, pp. 953-959, October 1999.

[3]. Sung-Chan Ahn and Dong-Seok Hyun "New Control Scheme of Three-Phase PWM AC/DC Converter without Phase Angle Detection under the Unbalanced Input Voltage Conditions" IEEE transactions on power electronics, VOL. 17, NO. 5, pp. 616-622, September 2002.

[4]. X. H. Wu , S. K. Panda and J. X. Xu "Design of a Plug-In Repetitive Control Scheme for Eliminating Supply-Side Current Harmonics of Three-Phase PWM Boost Rectifiers Under Generalized Supply Voltage Conditions" IEEE transactions on industrial electronics, VOL. 25, NO. 7, pp. 1800-1810, July 2010.

[5]. Ana Vladan Stankovic and Ke Chen "A New Control Method for Input-Output Harmonic Elimination of the PWM BoostType Rectifier Under Extreme Unbalanced Operating Conditions" IEEE transactions on industrial electronics, VOL. 56, NO. 7, pp. 2420-2430, July 2009.

[6]. Hamid Eskandari-Torbati, Davood Arab Khaburi, and Vahid EskandariTorbati " Virtual Flux Based Direct Power Control (DPC) of Three Phase PWM Rectifier Using Model Predictive Control (MPC) and 
Space Vector Modulation (SVM)" The 5th Power Electronics, Drive Systems and Technologies Conference (PEDSTC 2014), Feb 5-6,2014, Tehran, Iran. pp. 242-248.

[7]. Rusong Wu, S.B. Dewan, and G.R. Slemon "A PWM AC to DC Converter with Fixed Switching Frequency" University of Toronto in Canada, 1988. pp. 706-711.

[8]. Muntadher K. Abdullah "Control Strategy for Three-Phase PWM Rectifier Operating under Different Supply Voltage Conditions", MSc thesis, Al-Mustansiriya University, 2014.

[9]. Keliang Zhou and Danwei Wang "Digital Repetitive Controlled Three-Phase PWM Rectifier" IEEE transactions on power electronics, VOL. 18, NO. 1, pp. 309-316, January 2003.
[10]. Wenzhou LU, Keliang ZHOU, and Yunhu YANG "A General Internal Model Principle Based Control Scheme for CVCF PWM Converters" 2010 2nd IEEE International Symposium on Power Electronics for Distributed Generation systems. pp. 485-489.

[11]. G. Escobar, J. Leyva-Ramos, P. R. Martínez, and A. A. Valdez "A RepetitiveBased Controller for the Boost Converter to Compensate the Harmonic Distortion of the Output Voltage" IEEE transactions on control systems technology, VOL. 13, NO. 3, pp. 500-508, May 2005.

[12]. Masoud Karimi-Ghartemani "Linear and Pseudolinear Enhanced Phased-Locked Loop (EPLL) Structures" IEEE transactions on industrial electronics, VOL. 61, NO. 3, pp. 1464-1474, March 2014. 